\title{
MENTALIDAD MORAL Y CONTRARREFORMA EN LA ESPAÑA MODERNA (FORNICARIOS, CONFESORES E INQUISIDORES: EL TRIBUNAL DE LOGROÑO, 1571-1623)*
}

\author{
POR \\ Fernando ChavarRía MúGica \\ Instituto Universitario Europeo, Florencia
}

\section{RESUMEN}

La Inquisición postridentina adquirió competencias sobre las proposiciones por «simple fornicación» generando así un importante caudal documental. A pesar de eso la historiografía ha tendido a obviarlo. Sin embargo es necesario detenerse en su estudio para analizar el papel que desempeñó la Inquisición dentro de la amplia estrategia contrarreformista y en este contexto poder comprender las resistencias y permeabilidades de la sociedad al nuevo modelo de disciplina moral.

PALABRAS CLAVE: Inquisición, Contrarreforma, Confesionalización, Disciplina social, Historia de la sexualidad, Control social, Manuales de confesores, Simple fornicación, Moral popular, Historia de las mentalidades.

* Tengo que agradecer al profesor Jesús Ma . Usunáriz Garayoa (Universidad de Navarra) su apoyo constante en la dirección de este trabajo, a mi compañero Javier Esquiroz Pernaut su inestimable ayuda en la consulta y transcripción de los fondos de la Biblioteca del Seminario Diocesano de Pamplona y por último al Dr. Miguel A. de Bunes Ibarra (C.S.I.C.) sus valiosos consejos. Este trabajo se enmarca dentro del proyecto de investigación: «Formas de vida, modos de creer: hacia una Historia Cultural de Navarra durante la Edad Moderna», financiado por el programa de apoyo a la investigación del Departamento de Educación y Cultura del Gobierno de Navarra.

Actitudes religiosas en la Edad Moderna Hispania Sacra 53 (2001) 


\begin{abstract}
The Inquisition acquired jurisdiction over the «proposals of simple fornication» after the Council of Trent. The historiography has tended to ignore this important flow of documentation whereas the study of this topic is necessary to analyse the role played by the Inquisition in the wide Counterreformation strategy in order to understand social resistance and permeability towards the new pattern of moral discipline.
\end{abstract}

KEY WORDS: Inquisition. Counterreformation, Confessionalization, Social Discipline, History of Sexuality, Social control, Manuals of confession, Simple fornication, Popular Morals, History of Mentality.

Han pasado más de noventa años desde que Henry Ch. Lea escribiera $A$ History of the Inquisition of Spain (Nueva York, 1906-1907) y muchas de sus conclusiones han permanecido vigentes hasta hace no demasiado tiempo. Este es el caso de los llamados delitos «menores» ${ }^{1}$ normalmente englobados en la categoría genérica de proposiciones:

«progresivamente bajo la denominación general de 'Proposiciones' [la Inquisición] desarrolló un extenso campo de acción, que hacia el fin llegó a constituir su principal función. [...] Por tanto, desde cualquier punto de vista, las diversas faltas agrupadas bajo el término general de 'Proposiciones' en modo alguno fueron el menos importante de los objetivos de la actividad inquisitorial».

En contra de lo que pudiera deducirse de esta afirmación, despachó el asunto en unas pocas páginas. Esto no hubiera tenido mayor relevancia si no fuera porque la historiografía posterior apenas ha prestado mayor atención al tema, limitándose prácticamente a aceptar y reproducir casi de forma literal las conclusiones de $\mathrm{Lea}^{2}$. Éste es precisamente el caso de las proposiciones por simple fornicación:

1 «La utilización de las fuentes documentales de manera parcial o acrítica puede conducir, entre otros errores, [...] a deformar la imagen del Santo Oficio amplificando los delitos mayores y las penas más duras, al tiempo que se minusvaloran los delitos menores y las formas menos cruentas de represión», advierte acertadamente Francisco Fajardo Spínola, «La actividad procesal del Santo Oficio. Algunas consideraciones sobre su estudio» en Manuscrits, $\mathrm{n}^{\circ}$ 17, 1999, pp. 97-117 (p. 110); algunas reflexiones adicionales sobre la importancia de estas causas «menores» en Jean-Pierre Dedieu, «The Inquisition and Popular Culture in New Castile» en Setephen Haliczer (ed.), Inquisition and Society in Early Modern Europe, Londres, 1987, pp. 129-146.

2 Un ejemplo de este desinterés podemos encontrarlo, 83 años después de la obra de H. Ch. Lea, en la monografía de S. Haliczer Inquisition and Society in the Kingdom of Valencia (1478-1834), Berkeley, 1990, p. 299, donde, después de remarcar su importancia para el desarrollo postridentino del tribunal, dedica un solo párrafo a la cuestión de la simple fornicación, repitiendo argumentos ya conocidos. Pero esto es solo un ejemplo significativo de una larga lista. 
«Aunque los teólogos sostenían que esta afirmación en sí misma era ya pecado mortal, nada había en ella realmente con sabor a herejía y su conocimiento por la Inquisición fue una arbitraria e injustificada extensión de su jurisdicción»³.

Desde entonces se ha escrito mucho sobre la Inquisición pero esa afirmación no fue matizada hasta que J.P. Dedieu demostró la conexión entre las directrices contrarreformistas y la persecución inquisitorial de los delitos de estados, bigamia y simple fornicación dentro de la campaña postridentina en defensa del sacramento del matrimonio, descartando así la «arbitrariedad injustificada» a la que aludía $\mathrm{H}$. Ch. Lea. Por su parte J. Contreras quiso ir un poco más allá al tratar de explicar el origen y las causas de esta cuestión. Pese a todo y aunque sigue insistiéndose en la presunta importancia de las proposiciones, son muy escasos los estudios sobre las numerosas causas incoadas por simple fornicación, todavía sistemáticamente obviadas. ${ }^{4}$ Por tanto es necesario prestar más atención a este asunto analizando sobre el terreno las circunstancias de los procesos: los testigos y los acusados, los temas que tratan y en qué términos, sus propias justificaciones, sus resistencias y permeabilidades. De este modo podremos situar el problema de la simple fornicación en su propio contexto, mucho más amplio que el estrictamente inquisitorial, para adentrarnos en el mundo de las relaciones de pareja, el matrimonio, la sexualidad y la moral durante los «tiempos recios» de la Contrarreforma. El presente artículo pretende cubrir de algún modo esta laguna ${ }^{5}$.

3 Henry Ch. LEA, A History of the Inquisition of Spain, Nueva York, 1906-1907 (edición española: Historia de la Inquisición española, Madrid, 1983, pp. 521 y 528).

4 Por supuesto no es este el primer trabajo sobre el tema, por lo menos cuatro artículos lo tratan específicamente: J. M. GARCÍA DE FUENTES, «Inquisición y sexualidad en el Reino de Granada en el siglo XVI» en Chronica Nova, 13, 1982, pp. 207-229; José Cobos RUIZ DE ADANA, «Sexualidad e Inquisición en Córdoba a fines del siglo XVI (1577-1595)» en Axerquia, 2, 1981, pp. 174-194; M. ${ }^{2}$ A. HERNÁNDEZ y I.M. ${ }^{a}$ Teston, «La sexualidad prohibida y el Tribunal de la Inquisición de Llerena» en Revista de estudios extremeños, vol. 44, nº 3, 1988, pp. 623-660; Stuart B. SCHWARTZ, «Pecar en las colonias. Mentalidades populares, Inquisición y actitudes hacia la fornicación simple en España, Portugal y las colonias americanas» en Cuadernos de Historia Moderna, 18, 1997, pp. 51-67. Mucho más importante es el artículo del citado Jean-Pierre Dedieu, «Le modèle sexuel: la défense du mariage chrétien» en Bartolomé Bennassar, L'Inquisition Espagnole, Paris, 1979, pp. 313-338 y también el capítulo dedicado a este aspecto en Jaime Contreras, El Santo Oficio de la Inquisición en Galicia, Madrid, 1982, p. 627 y ss. Algunas reflexiones generales sobre el tema en $M^{a}$. Helena Sánchez Ortega, «Un sondeo en la historia de la sexualidad sobre fuentes inquisitoriales» en J. PÉREZ VILLANUEVA (dir.), La Inquisición española: nueva visión, nuevos horizontes, Madrid, 1980, pp. 917-930. Prácticamente todas las monografías dedican un breve apartado al respecto de un modo más descriptivo que analítico.

5 Todas las citas documentales de este trabajo están tomadas de las causas inquisitoriales por proposiciones escandalosas y por simple fornicación correspondientes a la jurisdicción del tribunal de Logroño entre los años 1577 y 1620: Archivo Histórico Nacional, Inquisición, Relaciones de Causas, libs. 833-836. Por otra parte, esta documentación se complementa con la información obtenida de los 
En la era confesional, el establecimiento de dogmas firmes y sacramentos bien definidos no sólo planteaba dilemas teológicos. Las resoluciones espirituales iban necesariamente acompañadas de medidas materiales concretas que aseguraran de un modo $\mathrm{u}$ otro su viabilidad. La Iglesia tridentina, perfectamente consciente del estado de las cosas, planteó una estrategia de reforma profunda a varios niveles: respeto a lo sagrado y defensa del dogma como base del orden trascendente; refuerzo de los principios de autoridad y jerarquía, propios del orden eclesiástico; además del restablecimiento de un orden moral. Quedaba claro que el adoctrinamiento del cuerpo general de fieles en los principios fundamentales de la fe así como la inculcación de un modelo renovado de moralidad constituían una necesidad perentoria a la que era imposible renunciar a pesar de todas las dificultades ${ }^{6}$. Más aún en cuestiones tan resbaladizas como la simple fornicación.

Según explica el Dr. Martín Carrillo en su Memorial de Confessores (1602) «la fornicación, propiamente es el acceso y cópula de un soltero con soltera, aunque algunas veces en nombre de fornicación, se entienda todo acto libidinoso» ${ }^{7}$. Queda claro que aunque se refiera específicamente a las relaciones sexuales entre hombre y mujer libres de todo vínculo (afinidad, familiaridad, voto, etc.), este pecado se extiende de hecho a aspectos que no solo afectan a la cópula sino también a otros actos, así como a las palabras y a los pensamientos ${ }^{8}$.

siguientes manuales de confesores y tratados de teología moral procedentes de los fondos de la Biblioteca del Seminario Diocesano de Pamplona: Martín de Azpilicueta, Manual de confessores y penitentes, que clara y brevemente contiene, la universal y particular decisión de quasi todas las dudas, que en las confesiones suelen ocurrir de los pecados, absoluciones, restituciones, censuras \& irregularidades, 1556; Bartolomé de Medina, Breve instrucción o como se ha de administrar el sacramento de la penitencia dividida en dos libros, Pamplona, 1581; Manuel Rodríguez Lusitano, Summa de casos de consciencia con advertencias muy provechosas para confessores con un orden iudicial a la postre, en la qual se resuelve lo mas ordinario de todas las materias morales, Barcelona, 1596; Martín Carrillo, Memorial de confessores en el qual se refieren exemplos y lugares de la sagrada scriptura y de doctores: contra quales quiere vicios y pecados, y remedios contra ellos, Barcelona, 1602; Martín de Torrecilla, Suma llamada nueva recopilación y practica del fuero interior, utilisima para confesores y penitentes, con varias resoluciones de casi innumerables casos de conciencia, 1606; Enrique de Villalobos, Manual de confessores compuesto por el lector de Theología, jubilado, de San Francisco el Real de Salamanca, Madrid, 1687; Anselmo Gómez, El perfecto examen de confessores matritense, Madrid, 1676; Jaime de Corella, Suma de la Theologia moral, su materia, los tratados mas principales o casos de conciencia, Madrid, 1687; id., Practica de el confessonario y explicacion de las 65 proposiciones condenadas por la santidad de N.S.P. Inocencio XI, Zaragoza, 1688.

6 Cómo no ser consciente de las dificultades si la experiencia práctica ante los penitentes enseñaba a los confesores que «se trataba de personas con vicios y virtudes mezclados, unas arrepentidas, otras dubitativas, otras medio simuladoras, otras habituadas a desviaciones particulares», en Julio Caro Baroja, Las formas complejas de la vida religiosa (Siglos XVI y XVII), Madrid, 1985, p. 542.

7 MARTín CARRILLO, op. cit., capítulo X.

8 Jaime de Corella señala, por ejemplo: «La delectación del objeto lascivo, aun bajo la condición que le puede quitar la malicia no es lícita; v.g.a. Al soltero no es lícito deleitarse en la cópula,

Actitudes religiosas en la Edad Moderna

Hispania Sacra 53 (2001) 
No hay duda sobre la consideración pecaminosa de la fornicación puesto que atenta contra el sexto mandamiento de la ley de Dios y participar del tercer vicio capital, que es la lujuria. Por si acaso, Manuel Rodríguez Lusitano se encarga de precisar además que «está prohibida por el derecho divino, natural y positivo» ${ }^{9}$. Hasta aquí todo parece muy claro; la realidad sin embargo estaba muy alejada del ideal. Los propios confesores a través de los manuales reconocen que «este vicio es el que más daño hace en el mundo por ser más universal en él la pelea y más rara la victoria ${ }^{10}$. Las relaciones de causas de la Inquisición nos ofrecen también una multitud de referencias que hacen pensar en la extensión de este tipo de actitudes, como así lo atestiguan los más de 300 casos registrados en el tribunal inquisitorial de Logroño en el período más virulento, comprendido entre los años 1570 y 1620. Lo mismo ocurre en otros territorios peninsulares por las mismas fechas, ${ }^{11}$ tanto es así que algunos autores hablan para esta época de cierta «liberalidad en el otorgamiento» aceptada en comunidades rurales en general «sin excesivas connotaciones disfuncionales» ${ }^{12}$. Estas afirmaciones suscitan inmediatamente algunas preguntas de no fácil respuesta: ¿existió realmente tal «liberalidad? ¿Qué alcance tuvo? ¿Hay alguna razón que la explique? Pero no podemos adentrarnos en estas cuestiones si

\footnotetext{
bajo la condición de si estuviera casado: ni a la viuda es lícito deleitarse de la cópula pasada, pretendida bajo la condición del matrimonio pretérito», op. cit., Suma de la Theología moral..., p. 315.

9 Manuel RODRíGUEZ LuSITANO, op. cit., fol. 494.

10 Bartolomé DE MEDINA, op. cit., fol. 169.

11 Para una descripción de las vicisitudes del tribunal que nos ocupa ver Antonio Bombín Pérez, La Inquisición en el País Vasco: el tribunal de Logroño (1570-1610), Bilbao, 1997, y sobre el tribunal de Calahorra que lo precedió ver Iñaki Reguera, La Inquisición española en el País Vasco, San Sebastián, 1984. Además de las ya citadas (ver notas 2 y 4), contamos con multitud de obras de muy diversa extensión e importancia para muchos otros territorios de la Monarquía Hispánica: Ricardo GARCíA CÁRCEL, Herejía y sociedad en el siglo XVI. La Inquisición en Valencia (1530-1609); María PALACIOS AlCALDE, «La Inquisición en Écija» en Espacio, Tiempo y Forma. Historia Moderna, 4, 1991, pp.451-465; Sara T. Nalle, God in La Mancha. Religious reform and the people of Cuenca, 15001600, Baltimore, 1992, obra especialmente interesante al analizar en conjunto el impacto de la Contrarreforma en un territorio específico; William Monter, La otra Inquisición (La Inquisición española en la Corona de Aragón, Navarra, País Vasco y Sicilia), Barcelona, 1992; Juan BLÁZQUEZ MIGUEL, La Inquisición en Cataluña, Toledo, 1990; Flora GARCÍA IVARS, La represión en el tribunal Inquisitorial de Granada, 1550-1819, Madrid, 1991. Otros estudios relacionados: Isidro DUBERT, «Los comportamientos sexuales premaritales en la sociedad gallega del Antiguo Régimen» en Studia Historica (Historia Moderna), IX, 1991, pp. 117-142; Juncal CAMPO GUINEA, Comportamientos matrimoniales en Navarra (siglos XVI-XVII), Pamplona, 1998; M. a Ángeles HERNÁNDEZ BERMEJO, La familia extremeña en los tiempos modernos, Badajoz, 1990; Ángel RODRíGUEZ SÁNCHEZ, «Un proceso sin sentencia. Acusado y acusadores en la diócesis de Coria en 1591» en Espacio, Tiempo y Forma, 4, 1989, pp. 501-550; Rafael CARRASCO, «Herejía y sexualidad en el Siglo de Oro (Tristes sodomitas valencianos)», en Los cuadernos del Norte, 6/34, 1985, pp. 62-72; Francisco VÁZQUEZ GARCíA, «Historia de la sexualidad en España: problemas metodológicos y estado de la cuestión» en Hispania, LVI/3, nº 194, 1996, pp. 1007-1035.

12 Jaime CONTRERAS, op. cit., El Santo Oficio..., p. 628.
} 
antes no nos planteamos porqué se prestó a este fenómeno tan especial atención precisamente en aquel momento.

El problema era más complejo de lo que a simple vista pudiera parecer. La preocupación principal era que ese comportamiento no sólo se había convertido en costumbre para un amplio sector de la población sino que además había trascendido al terreno de las creencias. Domingo de Padrones fue acusado ante el tribunal del Santo Oficio de Logroño porque «trabajando en una heredad con otras personas y diciéndole una dellas que el reo debía de haber estado teniendo cuenta con alguna moza, el dicho reo respondió y dijo '¡Pues qué!, si me lo da no es pecado', y diciéndole era pecado y muy grande volvió a decir que no era mortal sino venial», teniendo que salir al auto celebrado en Logroño en 1584. Ese mismo año también tuvo que salir Diego de Ojeda por decir que «no era pecado tener que hacer con cierta moza que vio en el campo». Los abundantísimos ejemplos registrados siguen en líneas generales este planteamiento, aunque existen algunas variantes. Pasamos por tanto al delicado mundo de las palabras, las opiniones y las creencias. El fenómeno de las proposiciones por simple fornicación trascendía los límites de la intimidad moral para convertirse además en un problema social.

Es aquí donde surge el peligro de escándalo. Propiamente hablando este término se refería a la acción de incitar al pecado ya sea directa o indirectamente, es decir, proponiendo a otro cometer un pecado o cometerlo uno mismo de forma que otros pudieran tomar mal ejemplo:

«Síguese también de lo dicho, que cuando juntamente con el pecado hubo escándalo, está obligado el penitente a confesar aquella circunstancia, porque agrava mucho el pecado», ya que puede ocurrir que al pecar «los súbditos tomasen ocasión para hacer otro tanto»13.

Pero sin duda alguna lo que más desazón causa es la inducción pública y explícita a cometer un pecado, no movido por el placer o el beneficio sino buscando la «ruina espiritual» del prójimo ${ }^{14}$. La represión de este tipo de manifestaciones es la principal labor de la Inquisición. Aun hay más, el celo ha de guardarse siempre y en toda circunstancia «porque no solamente del pecado, pero aun de lo que comúnmente parece como tal, nos hemos de guardar.»15

13 Bartolomé DE MEDINA, op. cit., fol. 18.

14 Anselmo GÓMEZ, op. cit., fol. 85.

15 Martín DE AZPILICUETA, op. cit., fol. 16.

Actitudes religiosas en la Edad Moderna

Hispania Sacra 53 (2001) 
No basta ser buen cristiano, también hay que parecerlo. La ambigüedad no podía tolerarse en la era confesional ${ }^{16}$.

En el caso del pecado de simple fornicación estaba en juego la defensa del sacramento del matrimonio, asentado sobre los siguientes principios básicos: indisolubilidad, monogamia, prohibición terminante de cualquier tipo de relación sexual extraconyugal y la consideración de la castidad como un estado superior al matrimonial en dignidad y perfección. Estos principios no eran nuevos pero es ahora cuando quedan establecidos mediante un conjunto de prácticas concretas. Someterse a esta disciplina significaba estar integrado en la ortodoxia confesional y lo contrario, estar excluido, con todo lo que eso conllevaba. Cualquier opinión que los contraviniera directa o indirectamente estaría negando el sacramento y, por lo tanto, uno de los pilares fundamentales de la Iglesia católica tridentina. Es decir, mantener una opinión o creencia desviada hacía que un fiel pasara de ser tolerado como pecador a ser perseguido como hereje. Desde este punto de vista, como bien señaló Dedieu, puede explicarse la intervención de la Inquisición en este tipo de materias (bigamia, simple fornicación y las desviaciones sexuales) y en otras que pudiesen atentar contra los principios sobre los que se apoyaban otros sacramentos (de ahí la persecución de delitos como el de estados o blasfemias). Siguiendo este razonamiento, las Cartas Acordadas del 20 de noviembre de 1573 y 1574 ordenaban incluir la simple fornicación entre los delitos enumerados en el edicto de fe, aplicando así el mismo procedimiento que contra cualquier proposición herética. ${ }^{17}$ Lo que demuestra la voluntad explícita de perseguir estas actitudes ${ }^{18}$.

16 Ricardo García Cárcel define confesión de esta manera: «la unidad corporativa y gregaria de fieles, una doctrina asumida dogmáticamente con su código de normas estandarizadas y la función pública del hecho religioso (el compromiso de la definición, la ecuación ser-parecer ser)», y disciplina: «la declaración de obediencia presta, automática e incondicional al credo doctrinario, vinculada a la unidad confesional», en «De la Reforma Protestante a la Reforma Católica. Reflexiones sobre una transición» en Manuscrits, $\mathrm{n}^{\circ} 16,1998$, pp. 39-63. Ambas definiciones han sido tomadas, como el propio autor admite, de la historiografía alemana, principalmente Schilling, Oestreich y Reinhard, detrás de los cuales puede percibirse la decisiva influencia de los estudios sociológicos de Max Weber y Norbert Elias. Para un balance del debate alrededor de los conceptos de confesionalización y disciplina social vid. Wolfgang REINHARD, «Disciplinamento sociale, confessionalizzazione. Un discorso storiografico» y Heinz SCHILLING, «Chiese confessionali e disciplinamento sociale. Un bilancio provvisorio della ricerca storica», ambos en P. Prodi (ed.), Disciplina dell'anima, disciplina del corpo, disciplina delle società tra medioevo ed età moderna, Bolonia, 1994, pp. 101-123 y pp. 125-160, respectivamente; un buen estado de la cuestión en español: Federico PALOMO, «'Disciplina christina' Apuntes historiográficos en torno a la disciplina y el disciplinamiento social como categorías de la historia religiosa de la alta edad moderna», en Cuadernos de Historia Moderna, $\mathrm{n}^{\circ}$ 18, 1997, pp. 119-136.

17 Jean-Pierre DEDIEU, op. cit., p. 327.

18 Extracto de la Carta Acordada del 2 de octubre de 1574 (A.H.N. Inquisición, libro 497, Acordada 96, folio 159): «En vista de las relaciones que vienen al Consejo de causas despachadas en autos de fe, se entiende de la mucha frecuencia que hay en el delito de decir que la simple fornicación 
De este modo el Santo Oficio ya no se preocupará únicamente de la herejía formal definida, sino de las ideas y actitudes que pudieran llegar a sustentarla. Estas prevenciones iban encaminadas a evitar la posibilidad misma de que ésta pudiera arraigar, atacando la raíz del problema ${ }^{19}$. Es cierto que esta medida era teológicamente muy rigurosa, sin embargo, y pese a la polémica «probabilista» ${ }^{20}$, los confesores no dudaron en calificar esta opinión como herejía: «si un soltero tiene que ver con soltera esta se llama simple fornicación, y es pecado contra derecho natural: y quien dice lo contrario es hereje» ${ }^{21}$.

La eficacia de la campaña reformadora iba a depender de los distintos métodos que habrían de utilizarse para erradicar prácticas arraigadas e inculcar una nueva actitud hacia el matrimonio, la moral y la sexualidad. La Iglesia contará en este caso con dos instrumentos excepcionales para llevar a efecto tan delicada tarea: Inquisición y confesión, actuando en mutua connivencia con una síntesis de métodos coercitivos y persuasivos. Esta relación no es desde luego casual. Tiene su origen en la bula que el 5 de enero de 1559 otorgaba al Gran Inquisidor español Valdés el poder de absolver los pecados de herejía, hasta entonces reservado a los obispos. De este modo lo primero que los confesores tenían que preguntar a los penitentes era si habían cometido delitos pertinentes a la Inquisición o si poseían información útil para ésta; en caso afirmativo el confesor debía remitirlo al tribunal de la fe para obtener la abso-

no es pecado. Se ha hecho diligencia para entender si los dichos delincuentes tienen error en el entendimiento. Parece que en todos hay delincuencia y los más se fundan en la permisión de las mujeres públicas y [...] para remediarlo este año publiquen edictos particulares en todos los lugares de ese distrito como que este delito es herejía condenado por la Santa Iglesia y que los que la dijesen, creyesen o tuviesen, serán castigados como herejes» citada por Flora GARCÍA IVARS, op. cit. p. 43.

19 Para un ejemplo de cómo ciertas actitudes populares podían terminar convergiendo con ideas heréticas formales ver John MARTIN, «Popular Culture and the Shaping of Popular Heresy in Renaissance Venice» en S. HALICZER (ed.), op. cit., pp. 115-128.

20 La agria polémica probabilista, reflejada en los manuales de confesores que proliferan en este período, es una prueba de que la confusión doctrinal de entonces no sólo afectaba a los fieles incultos. Fray Anselmo Gómez regañará a otro doctor contemporáneo porque su opinión «no es doctrina que se pueda practicar en el confesionario, ni enseñar el día de hoy» y un poco antes comenta al respecto que «aunque en otras materias, y aun en ésta, especulativamente se pueda discurrir así [...] este discurso es bueno para la Cathedra, donde se hacen intenciones Lógicas, y se prescinden formalidades metaphisicas», op. cit., fol. 126 y 127. Sobre manuales de confesores vid. Arturo MORGADO, «Pecado y confesión en la España Moderna. Los manuales de confesores» en Trocadero, 8-9, 19961997, pp. 119-148; sobre la historia y desarrollo de la teología moral vid. John MAHONEY, The Making of Moral Theology, Oxford, 1981; sobre los orígenes y líneas fundamentales de la polémica entre «probabilismo» y «rigorismo» vid. Julio CARO BAROJA, op. cit., pp. 535-586; sobre la influencia y desarrollo de la casuística en el protestantismo y catolicismo vid. Jean DELUMEAU, «Prescription and Reality» y John Bossy, «Moral arithmetic: Seven sins into ten Commandments» ambos en Edmund Leites (ed.), Conscience and Casuistry in Early Modern Europe, Cambridge-París, 1988, pp. 134-158 y pp. 214-234, respectivamente.

21 Bartolomé DE MEDINA, op. cit., fol. 95. 
lución ${ }^{22}$. La simbiosis entre el confesionario y el Santo Oficio quedaba oficialmente instituida. La confesión, practicada regularmente, se convertía así en algo más que el sacramento de la penitencia; aliado con la Inquisición, era ahora un formidable instrumento de control social. Este mecanismo, como veremos, será como la punta de lanza de la reforma moral tridentina.

La base que fundamentará esta nueva forma de religiosidad será la práctica explícita y frecuente de los sacramentos, el respeto hacia ellos y la subordinación a la Iglesia como única garante de la pureza de la fe. Todos los fieles debían someterse a partir de entonces a esta disciplina sacramental, no sólo para participar de la gracia divina sino para demostrar precisamente su «catolicidad», y por tanto su lealtad a la Iglesia de Roma y en segunda instancia a la Monarquía Católica. La amenaza protestante era grave, aunque más en Italia que en España, por eso era necesario que los laicos manifestasen su fidelidad a la estructura eclesiástica de un modo explícito, es decir, controlable ${ }^{23}$. De este modo comprobamos que detrás de una moral relajada más o menos extendida y una mayor o menor ignorancia doctrinal subyacen otras razones que explican el interés de la Iglesia en este tema durante el último tercio del siglo XVI.

En ciertos casos se llega aun más lejos. El tribunal de la Inquisición no dudará en relacionar esta creencia con el luteranismo, algo que cuando menos resulta chocante. La proposición de Joan Pérez, que consideraba que no había pecado en la cópula carnal con viuda o soltera pagada y por tanto no era necesario confesarlo, fue calificada como «herética lutherana», por lo que fue condenado a salir al auto, abjuración de levi y una multa de 20 ducados. Este caso contrasta con el de Luis Huillo. El tal Luis era un sastre, vecino de Logroño pero nacido en Borgoña. Fue acusado en 1584 porque solía bailar y cantar en lengua francesa burlas contra curas y frailes, diciendo que estos se podían casar y que no era pecado «tener conversación carnal un hombre con una mujer mundana.» En las audiencias que se tuvieron confesó todo lo testificado y declaró ser protestante, reafirmándose en su posición. La pena es fácil de imaginar: salida al auto, confiscación de bienes y relajación en persona «por la secta de luthero.» Los dos casos son muy distintos entre sí. Si bien es obvio que Luis Huillo no fue ejecutado por defender la simple fornicación ¿sería posible establecer algún tipo de relación?, ¿Cuál era la base real que justificaba la calificación de ciertas proposiciones por simple fornicación como luteranas?

22 Adriano PROSPERI, «Notas sobre Inquisición» en Manuscrits, $\mathrm{n}^{\circ}$ 17, 1999, pp. 31-37; del mismo autor vid. ADRIANO PROSPERI, Tribunali..., op. cit. donde estudia profusamente la relación entre confesión, Inquisición y actividad misional como estrategia de la Reforma Católica de lucha contra la herejía y de control social para el caso de Italia.

23 Adriano PROSPERI, Tribunali della coscienza (inquisitori, confessori, missionari), Turín, 1996, p. 275. 
A la vista de los testimonios de los Reformadores protestantes no tiene sentido afirmar una posible relación entre sus críticas o sus doctrinas y la extendida creencia de la inocuidad moral de la simple fornicación ${ }^{24}$. De hecho sus propagandistas establecieron la misma correlación respecto de los católicos: papismo $=$ corrupción. En un principio el protestantismo asumirá una actitud moral mucho más rígida y radical (conceptual y prácticamente) en comparación con el catolicismo. Desde este punto de vista «el fornicador protestante no podía comprar una salida a su culpabilidad por medio de la penitencia, la absolución del cura después de la confesión no tenía significado alguno. María Magdalena era solo una leyenda católica carente de autenticidad en las escrituras. La mujer caída era un agente del demonio y la mancebía pública una marca de la sociedad impía» ${ }^{25}$. Dicho y hecho, en la medida en que a principios del siglo XVI diferentes estados adoptaron como propia la confesión protestante se inició una campaña de persecución contra la prostitución y se procedió al cierre de los burdeles públicos, aunque solo en Holanda y Ginebra se perseguirá la fornicación como un delito criminal ${ }^{26}$. Algo muy distinto

24 « ¿Cuídense pues todos del adulterio y de la fornicación! ¡No toleraremos en nuestro medio tales pecados!» exhortará Martín Lutero en su sermón sobre «La agradecida estimación del estado matrimonial» (8 de enero de 1531) en Obras completas de Martín Lutero, Buenos Aires, 1983, tomo IX, p. 386.

25 Olwen Hufton, The Prospect before Her (vol. I, 1500-1800), Nueva York, 1996, p. 309 (traducido del inglés).

26 En toda Europa occidental se percibe un creciente interés por el control de la moral pública, el matrimonio y la sexualidad, patente a partir del siglo XVI, tanto en el ámbito católico como protestante, aunque manifestado de diverso modo. Una muestra de ello la dan historiadores como Jean-Louis FLANDRIN, Le sexe et l'Occident (Évolution des attitudes et des comportements), París, 1981 o Lawrence Stone, Family, Sex and Marriage in England, 1500-1800, Londres, 1977, opiniones de las que se hace eco Martin INGRAM, «The Reform of Popular Culture? Sex and Marriage in early modern England» en Barry Reay (ed.), Popular Culture in Seventeenth-century England, Londres, 1988, pp. 129-165. Las mismas ideas sostiene Carol KAZMIERCZAK MANZIONE, «Sex in Tudor London: Abusing their bodies with each other» en Jaqueline MURRAY y Konrad EISENBICHLER (eds.), Desire and Discipline: Sex and sexuality in the Premodern West, Toronto, 1996, señalando que las autoridades londinenses se esforzaron por controlar y limitar la sexualidad mucho antes de la Guerra Civil inglesa y la revolución puritana. Sobre Inglaterra también vid. Martin Ingram, Church Courts, Sex and Marriage in England (1570-1640), Cambridge, 1988. En otras áreas de Europa como Alemania hay que retroceder hasta la época de la Reforma para estudiar el origen de este ansia de control de la moral pública, vid. Lyndal ROPER, The Holy Household: women and morals in Reformation Augsburg, Oxford, 1989; id., «'The common man', 'the common good', ' common women': gender and meaning in the German Reformation commune» en Social History, 12-1, 1987, pp. 1-22; Ulinka RUBLACK, The crimes of Women in Early modern Germany, Oxford, 1999; Thomas Robisheaux, «Peasants and pastors: rural youth control and the Reformation in Hohenlohe, 1540-1680» en Social History, 6, 1981, pp. 281-300. Para el caso francés vid. Jacques SOLÉ, L'amour en occident a l'epoque moderne, París, 1976; Jean-Louis FlANDRIN, Les amours paysannes (XVIe-XIXe siècle), París, 1975; R. MUCHEMBLED, Culture populaire et culture des élites dans la France moderne (Xve-XVIIIe siècles): 
de la tibieza que en este aspecto y por aquel tiempo mostraba el mundo católico en general. El único punto de disensión realmente serio entre ortodoxia y herejía a este respecto era la defensa de un nuevo concepto de matrimonio situado en un nivel de dignidad mayor que el del sacerdocio (aunque negando su carácter sacramental), convirtiéndose por tanto en un estado universalmente deseable, incluso para el estamento religioso. Los panfletistas protestantes criticarán duramente el celibato clerical, denunciando al mismo tiempo la hipocresía de la Iglesia al tolerar prostíbulos y concubinas. Más aun, contra las críticas a la vida matrimonial argüirán que no eran nada más que excusas y falsos miedos para rehuir la responsabilidad de imponerse una autodisciplina a través del matrimonio monogámico ${ }^{27}$.

De cualquier modo, parece ser que en este aspecto la explicación no sería tanto doctrinal como de tipo sociológico. El mundo católico, como lo hará el protestante en sus diversas variantes, creará un «modelo cultural» ${ }^{28}$ apoyándose en la nueva concepción de la religión, que de hecho afectará a todos los ámbitos de la sociedad. La identificación con este modelo se creará no sólo basándose en una nueva visión de sí mismos sino sobre todo en contraposición a otro colectivo. La atribución de caracteres disfuncionales de índole moral vendría no sólo a definir al «otro» (la «herejía lutherana») sino que al mismo tiempo reforzaría la posición propia (la ortodoxia tridentina). El resultado es una polarización de ambas sociedades percibidas entre sí como antagónicas pese a que, en la práctica, sus actitudes sobre este aspecto tiendan a confluir con el tiempo ${ }^{29}$.

¿Pero quién era ese fornicador que se presentaba en el confesionario y comparecía ante la Inquisición? Si hablamos de la mayor proporción de casos el típico «simple fornicador», el que defendía dichas creencias, podría responder al siguiente perfil: hombre soltero, campesino rústico, cristiano viejo de unos 30 años. Aun sin rechazar lo anterior, que no es más que una evidencia

essai, París, 1979; Raymond A. MENTZER, «Morals and Moral Regulation in Protestant France» en Journal of Interdisciplinary History, XXXI:I, verano, 2000, pp. 1-20. La vestimenta, el mobiliario y el espacio doméstico también podían ser instrumentos de autocontrol moral: Olivier CHRISTIN, «Leçon de choses» en Actes de la recherche en sciences sociales, $\mathrm{n}^{\circ} 128,1999$, pp. 80-90. Desde una perspectiva teórica es ineludible citar el ensayo clásico de Michel FoUCAULT, Histoire de la sexualité. I. La volonté de savoir, París, 1976.

27 Steven OzMENT, When Fathers Ruled, Cambridge (Mass. EE.UU) - Londres, 1983, pp. 4-7.

28 El término ha sido tomado de Jaime CONTRERAS, Aspectos metodológicos y teóricos para el estudio de la religiosidad popular, ponencia presentada en el Departamento de Historia de la Universidad de Navarra, 1999 (inédito).

29 Sobre la definición de identidades nacionales-religiosas por «oposición» vid. Tony CLAYDON e Ian MCBRIDE, «The trials of the chosen people: recent interpretations of protestantism and national identity in Britain and Ireland» así como el resto de trabajos incluídos en ídem (eds.), Protestantism and National Identity (Britain and Ireland, c.1650-c.1850), Cambridge, 1998, pp. 3-29. 
obvia, no podemos ignorar otros muchos casos que si bien son menos abundantes no por ello son marginales y, en cualquier caso, resultan muy significativos.

Algunos historiadores han señalado respecto a otros territorios la marcada ruralidad o la vida desarraigada como rasgos característicos de los encausados por simple fornicación ${ }^{30}$. Pero el análisis de la documentación correspondiente al tribunal de Logroño nos permite ofrecer una visión mucho más matizada. Por una parte es cierto que abundan los casos de personas relacionadas con actividades profesionales eminentemente rurales: labradores, jornaleros y pastores. Un ejemplo típico podría ser el de Lorenzo de Morras, labrador de 22 años, vecino de la villa de Los Arcos, el cual «tratando de cosas de mujeres dijo que no era pecado tener que hacer con una mujern. Sin embargo, un examen más detenido nos muestra que este tipo de casos no llega ni al 50\% del total de causas en las que se especifica el oficio del reo. Así encontramos una variedad de actividades notable: bordadores, pañeros, zapateros, estudiantes, arrieros, soldados, clérigos, escribanos, molineros e incluso un verdugo. $\mathrm{Si}$ a esto añadimos que aproximadamente un $15 \%$ de los encausados vivían en ciudades (Logroño, Tudela, Pamplona, Vitoria...) y un $25 \%$ en villas de cierta importancia (Bilbao, Alfaro, Santander...), podemos por lo menos poner en duda la eminente ruralidad de este fenómeno.

Por otra parte, podemos comparar todos estos datos con los correspondientes al nivel de riqueza e integración de los encausados en su localidad. Una mayoría aplastante está avecindada en la localidad en la que reside dentro de la jurisdicción del tribunal de la Inquisición de Logroño. Una minoría proviene de otras partes de España o del extranjero pero la mayor parte de ellos reside de forma estable en una villa o ciudad relevante. También son minoritarias las ocupaciones itinerantes o inestables: soldados, arrieros y algún clérigo descarriado y aun dentro de estos grupos la situación no es uniforme. Del portugués Gonzalo López se dice en la Relación de Causas de 1594-1595 que «anda vagante», siendo el único caso de este tipo registrado para todo el período. Examinando las penas pecuniarias ${ }^{31}$ impuestas por el tribunal encontramos una variedad notable de situaciones: desde los 300 ducados que tuvo que pagar el hidalgo Juan García, vecino de Mañeru, en 1588 hasta los 4 del calcetero Juan de Miranda, vecino de Estella, en 1590. Pero dentro de un mismo estrato encontramos también importantes diferencias. El labrador Miguel Merino por

30 «Hombres rústicos, labradores ignorantes, mundo rural en general; éste parece ser el entorno sociológico donde la simple fornicación apenas despierta escrúpulos colectivos» dirá Contreras para el caso de Galicia, op. cit., El Santo Oficio..., p. 629, para el caso de Toledo Dedieu dirá «Au lancement de la campagne, les coupables apparaissent en bonne partie comme des marginaux: un tiers d'étrangers, trois quarts de migrants...», op. cit., p. 329.

31 Presentes casi en el $30 \%$ de las sentencias. 
decir que «tener acceso y cópula carnal con mujer pública no era pecado» fue reprendido gravemente, abjuró de levi, oyó misa como penitente, fue desterrado por un año y tuvo que pagar 1000 maravedíes, mientras que el también labrador Pedro Carro tuvo que salir al auto de 1586 y pagar 8000 maravedíes por una proposición muy similar. Las multas variaban a discreción del tribunal, registrándose únicamente 23 casos en los que el reo declara ser manifiestamente pobre y, por tanto, eximido del pago. Por todo ello tampoco podemos establecer una correlación directa entre los perseguidos por simple fornicación y una situación de desarraigo o pobreza.

La distribución espacial resulta menos esclarecedora. Se registran casos en poblaciones y comarcas de lo más dispar (costa, interior, llanura, montaña...) y en todos los casos los patrones de comportamiento son muy similares. No existen peculiaridades geográficas en este sentido. Pero su distribución no es desde luego uniforme. Un gran número de casos se concentra en Logroño (sede del tribunal) y su provincia así como en la Ribera Navarra, Tierra Estella y la llanada alavesa. Estas comarcas son las más cercanas a la sede del tribunal y cuentan con una red más tupida de familiares y comisarios del Santo Oficio ${ }^{32}$. No debemos olvidar que ésta es una de las zonas más pobladas y dinámicas de su jurisdicción durante la época. Otros puntos de actividad que merezcan reseñarse son los correspondientes a la zona costera, sobre todo en torno a Bilbao y San Sebastián. Los casos se dispersan por todo el territorio y aparecen aquí y allá esporádicamente. Esto no puede interpretarse de ningún modo como una ignorancia generalizada del asunto, como de hecho nos muestran las intermitentes visitas de los inquisidores a los distritos ${ }^{33}$. Es en esos momentos cuando parece salir a la luz el problema, latente hasta entonces.

Un buen número de reos alega ignorancia y rusticidad como posible atenuante ante el tribunal inquisitorial, pero lo cierto es que en muy pocas ocasiones consigue probarse lo suficiente como para ser tenido en cuenta en la sentencia. Así por ejemplo, Juan de la Torre de 27 años alegó «ser rústico y de poca memoria por una herida en la cabeza», pero los testigos lo negaron, por lo que no se libraría de salir al auto de 1583 , ni de abjurar de levi, ni de los cien azotes, ni del destierro por un año, si bien no se le impuso pena pecuniaria por ser pobre. Parece ser que el tribunal del Santo Oficio de Logroño se tomó muy en serio la persecución de este delito a juzgar por el número de casos registrados y los castigos ejemplares impuestos, principalmente en las últimas décadas del siglo XVI. De hecho la extensión del fenómeno fue percibida por los propios contemporáneos, afectando de un modo u otro a todos los ámbitos

32 M. Ángeles CRISTÓBAL, «La Inquisición de Logroño: una institución de control social» en Jaime Contreras (ed.), Inquisición española, nuevas aproximaciones, Madrid, 1987, pp. 137-140.

33 ibid., pp. 140-142. 
y grupos sociales casi sin excepción. Martín de Azpilicueta hace el siguiente comentario a propósito del pecado capital de lujuria:

«De donde se sigue, cuanto (más que los otros) se ha de alejar deste sucio y viscoso vicio todos los contemplativos (que son clérigos y religiosos) todos los letrados, todos los gobernadores, capitanes y jueces» 34 .

Insiste en esto no porque la fornicación fuera necesariamente más común entre estas personalidades sino porque entre éstas hay mayor «necesidad de prudencia, sciencia, providencia, consejo, circunspección y constancia». Está claro que no siempre el comportamiento de autoridades y personalidades con ciertas responsabilidades era ejemplar y de hecho los pecados de éstos bien pudieron servir para justificar los propios: Domingo Cuadrillero dijo en Nájera «que los reyes y grandes señores tienen acceso y amistad y duermen carnalmente con sus parientas y que en respecto desto él lo había de hacer». Si esto se podía decir de reyes y Grandes quién no se burlaría de personajes más cercanos, como hizo Mari Saenz de Eraso al decir que «los más de los clérigos no se podían salvar» ${ }^{35}$.

Otro argumento tópico podría ser el de la edad. Encontramos reos de todas las edades, desde el canónigo de Vitoria Diego de Esquivel de 85 años hasta el sastre Francisco Garrido de 18 y, en todos los casos, las proposiciones son muy similares. Resulta difícil tipificar la censura de la simple fornicación como un asunto concerniente a las capas de población más joven cuando la horquilla de edad es tan amplia, ya que el $90 \%$ de los casos comprende reos entre 17 y 50 años. Si lo desglosamos en diferentes tramos ${ }^{36}$ : casi un $30 \%$ de los casos corresponde a menores de 25 años, algo más de un 35\% se encontraría entre los 25 y 35 y un $25 \%$ entre los 36 y 50 años. El número de casos registrados correspondientes tanto a adolescentes (menores de 20 años) como a ancianos (mayores de 65) es mínimo. Aunque se advierte un declive marcado a partir de los 45 años, más acusado a partir de los 50, la cantidad de testimonios, repartidos en tramos de edad en proporciones bastante parecidas, y la similitud de sus manifestaciones no nos permiten afirmar que la edad sea un

34 Martín DE AZPILICUETA, op. cit., fol. 490.

35 Bromeando con unos vecinos vino a decir «que los más de los clérigos no se podían salvar» recordando lo que «en tiempos antiguos un tío suyo clérigo cura y beneficiado en la anteiglesia de Aranzazu le había dicho: que se desviasen de los clérigos, porque las amigas de los clérigos no se podían salvar»; Mari Saenz de Eraso (mujer de Martín de Eraso, vecina de la anteiglesia de Galdácano, 60 años de edad, llamada a una audiencia y despachada sin sentencia, 1620).

36 Tomamos como primer punto de referencia la edad de 25 años ( 21 en el caso de las mujeres) siguiendo el mismo criterio empleado por el Santo Oficio a la hora de clasificar los testigos por su edad. 
factor determinante, ni siquiera un elemento característico, en los casos de simple fornicación.

Algo más difícil de valorar es el estado civil de los reos, ya que pocas veces se registra para el siglo XVI, pero podemos encontrar de todo: viudos, casados, solteros, clérigos... Sólo en el caso de estos últimos y de las mujeres el estado se especifica sistemáticamente. Aunque el número de encausadas es realmente bajo, su distribución por edades, su estado, su ocupación o la de sus maridos, su lugar de procedencia así como el contenido de sus proposiciones vienen a confirmar, en líneas generales, todo lo dicho hasta ahora. María de la Cruz de Portugalete, moza de 21 años por casar, fue testificada en 1586 porque «siendo reprendida porque andaba deshonestamente con un mozo y dormía carnalmente con él, respondió que no importaba, que ella y él eran libres». Sucedía otro tanto con la opinión sobre la prostitución, tal como declaró Magdalena López, mujer de Diego Martínez: «no es pecado la simple fornicación si luego se le paga a esa mujern, condenada a salir al auto de 1610 . En cualquier caso resulta muy difícil evaluar la verdadera participación femenina en este tipo de causas, más aun si hablamos no tanto de hechos sino más bien de opiniones y actitudes. A esto hay que añadir, aunque en sentido inverso, la más que notable presencia femenina en las causas, no ya como reos, sino como testigos o víctimas ${ }^{37}$.

A partir de lo expuesto podemos extraer algunas conclusiones. En primer lugar, no es raro encontrar gente con un buen pasar, tanto en el caso de campesinos y burgueses como en el de hidalgos, pero también a individuos pobres a los que no se les impone pena pecuniaria. Por otra parte, el origen de los reos no es desde luego únicamente rural, hay un buen número de artesanos e incluso podemos apuntar casos concernientes a estudiantes y a algunos clérigos. Procesos como los del labrador Alonso Moreno ${ }^{38}$ o el del bordador Diego López, ${ }^{39}$ demuestran que tanto en el ámbito rural como en el urbano las proposiciones por simple fornicación tratan de los mismos asuntos y son formuladas en los mismos términos. Es verdad que en las ciudades las posibilidades de control eran mayores y en este sentido es cierto que las resoluciones del Concilio de Trento pudieron implantarse allí con más facilidad y profundidad. También lo es que se percibe cierto retraso en su implantación en valles, aldeas y

37 En las Relaciones de Causas también se registran algunos casos de acoso y abuso sexual, como el de la viuda Catalina de Losantos (1594-1595).

38 Alonso MORENO (labrador, vecino de Comeno, auto de 1583): «estando en la feria de Nájera dijo tratando de las mujeres del partido que hay allí, que ir a ellas y tener acceso carnal con ellas no era pecado.»

39 Diego López (bordador, vecino de lo Logroño del barrio de Armiñón, 1580-1582): «había dicho que por tener que hacer carnalmente un hombre con una mujer no era pecado, y reprendiéndole uno de los dichos testigos diciéndole que no hablase aquello y que estaba dicho por la Inquisición que no se dijese, dicho López había respondido quel no lo tenía entendido así.» 
lugares, motivado más por carencias materiales y limitaciones físicas y de organización, subsanables con el tiempo, que por razones de otra índole, como pudiera ser el desarrollo de comportamientos sexuales y morales específicamente rurales. Por lo tanto no se puede afirmar que la triple correlación rusticidad-ruralidad-laxitud moral haya existido en oposición a su correspondiente urbano, educación-urbanidad-rigor tridentino, como si fueran dos realidades aisladas y enfrentadas una a la otra que irían desarrollándose paralela y divergentemente.

Ninguno de los parámetros analizados determina una especificidad moral o conceptual atribuible a un colectivo definido. Parece ser de hecho que este asunto afectaba a una capa de población numerosa y relativamente heterogénea que asumía o toleraba ciertos comportamientos sexuales sin otorgarles connotaciones morales especialmente negativas ${ }^{40}$. Me atrevería a afirmar incluso que este grupo pudo haber sido mucho más numeroso, sino mayoritario, en una época anterior al comienzo de las reformas, católica o protestante. La simple fornicación por tanto no era patrimonio exclusivo del mundo rural ni de gente especialmente mísera o ignorante.

Los testimonios de los acusados por el Santo Oficio nos muestran su progresiva permeabilidad al mensaje y la acción confesionalizadora derivados del Concilio. Hay que tener en cuenta que para el momento en el que comienza su actividad el Tribunal de Logroño, ya se había puesto en marcha un proceso de renovación eclesiástica en todo el área ${ }^{41}$. Pese a todo se perciben resistencias evidentes: «Parece tan claro, que la fornicación de su naturaleza no incluye malicia, y que solo es mala por prohibida, que lo contrario parece totalmente

40 «Bueno sería, padre, que todos los que van a la mancebía se fuesen al infierno», dirá sorprendido Diego Molero (pastor, vecino de Castelruiz, auto de 1592).

41 vid. José Goñi Gaztambide, Los navarros en el Concilio de Trento, Pamplona, 1947. Sobre el desarrollo de las sesiones y las deliberaciones del Concilio de Trento, especialmente en torno al «Decreto Tametsi» que es el que principalmente incumbe al presente artículo vid. Hubert JEDIN, Historia del Concilio de Trento, (4 tomos), Pamplona, 1972. Hubert Jedin establece distintas etapas en el proceso de renovación de la Iglesia, antes, durante y después del Concilio de Trento, basándose en dos ideas principales. Por una parte, la renovación interna de la Iglesia llevada a cabo desde el siglo XV que recibe su marco legal en Trento y que llamará «Reforma Católica». En segundo lugar la defensa de la Iglesia contra sus enemigos, que llamará «Contrarreforma». Claro está que estos dos aspectos no siempre podían separarse el uno del otro, según sintetiza John W. O'MALLEY, Trent and all that (Renaming Catholicism in the Early Modern Era), Cambridge (Mass.-EE.UU), 2000, p. 51. Por otra parte otros autores como James A. Brundage señalan que el Concilio de Trento supuso de hecho la culminación de un proceso más largo y complejo iniciado en 1215 durante el cuarto Concilio de Letrán, a partir del cual la Iglesia trató de fijar, lenta e irregularmente, un nuevo discurso respecto a su papel en la sociedad cristiana, vid. James A. BRUNDAGE, Law, Sex and Christian Society in Medieval Europe, Chicago, 1987.

Actitudes religiosas en la Edad Moderna Hispania Sacra 53 (2001) 
disonante a la razón» ${ }^{42}$. Esta creencia hubo de estar ciertamente muy arraigada para que aun en 1688 el Papa Inocencio XI tuviera que condenarla explícita y tajantemente. Sin embargo, bajo la aparente similitud de estas proposiciones se ocultan situaciones y motivaciones distintas. La Contrarreforma tratará de aclarar esta confusión generalizada y reducir las costumbres a una disciplina sacramental. La sexualidad no podía ser una excepción. Es precisamente en este contexto donde hay que situar la intensa campaña reformadora llevada a cabo desde el púlpito, el confesionario, los oficios religiosos y el tribunal de la fe. Algo que desde luego no resultaba fácil de aceptar para una amplia capa de la población. No se partía de cero. Los fieles ya tenían sus patrones de comportamiento respecto a la moral y la religión y sus conciencias no eran desde luego «tábulas rasas» listas para recibir los preceptos de la ortodoxia con la letra clara y firme del escriba tridentino.

En aquel período algunas prácticas en torno al matrimonio y la sexualidad fueron especialmente conflictivas. Trataremos fundamentalmente del amancebamiento, las promesas matrimoniales, las relaciones esporádicas, las mancebías públicas y el estado de viudedad.

A pesar de la tradicional tolerancia hacia el amancebamiento y su extendida práctica, este fenómeno será progresivamente percibido como algo socialmente disfuncional. Pese a todo encontraremos algunas resistencias. Catalina de Merodio, mujer de Pedro de Ardisana, fue acusada porque «entendía que no era pecado estar las personas de quien trataban amancebados y conocerse carnalmente, pues eran solteros y la justicia no lo castigaba, y reprendida dijo que lo había dicho por entenderlo así y que luego le pesó de ello». Ciertas actitudes hacia las uniones ilegítimas estables podrían haber tenido su origen en la costumbre medieval de desposarse por verba de futuro, es decir, bastaba con la promesa personal entre los amantes para que de hecho quedara legitimado un matrimonio. Sólo en un segundo momento se celebraría algún tipo de ceremonia formal y la bendición de dicha unión. Durante ese período de transición, entre la promesa y la ceremonia, se admitían relaciones entre los no$\operatorname{vios}^{43}$ y de hecho la cohabitación y el afecto mutuo eran pruebas suficientes que legitimaban una unión ante la comunidad ${ }^{44}$. Teniendo en cuenta que generalmente los contrayentes pertenecían a un mismo entorno, muy reducido, y la

\footnotetext{
42 Jaime DE CORELLA, op. cit., Practica de el confessonario..., fol. 282.

43 Pedro NUÑEZ (sastre, 1592-1593) fue a confesar ante el comisario de Ezcaray de este distrito:

«Que había dos años, poco más o menos, que estando en cierta parte del dicho lugar en compañía de ciertas personas acertó a llegar alli una moza y viéndola dijo el reo que cualquiera que tuviera acto carnal con ella no pecaba, y que al tiempo que dijo dicha palabra tenía intento de casarse con ella, y así lo hizo dentro derecho a quince días».

44 vid. James A. BRUNDAGE, «Concubinage and Marriage in Medieval Canon Law» en Journal of Medieval History, 1, 1975, pp. 1-17.
} 
temprana edad a la que se accedía al matrimonio, es lógico suponer por una parte, una relación previa entre ambas familias y, por otra, que la vida sexual prematrimonial quedara reducida al corto espacio restante entre la pubertad y la promesa. ${ }^{45}$ Cabe suponer también que la promesa desembocaría en la ceremonia de forma rutinaria, sin plantear necesariamente conflictos. Hay que tener en cuenta la validez legal de un juramento meramente oral en una sociedad en la que el compromiso escrito en la vida diaria quedaba restringido a límites más bien estrechos. El acceso al matrimonio estaba perfectamente regulado, por lo que no es posible pensar que aquellas gentes percibiesen negativamente dichas uniones, legítimas de hecho para todos aunque tardaran en formalizarse ante la Iglesia o nunca se llegase a dar este paso. Por tanto, en este contexto no cabe hablar estrictamente de «liberalidad en el otorgamiento», ya que si bien las uniones estaban sujetas a muy pocas trabas formales quedaban de hecho reguladas por las circunstancias previstas tradicionalmente y enmarcadas en la vida de la comunidad.

Pero este contexto cambiará drásticamente con el tiempo: las circunstancias ya no serán las previstas por la tradición aunque las costumbres perduren. La inestabilidad de este sistema era una fuente potencial de conflictos, como queda demostrado en los numerosos litigios por incumplimiento de promesas de matrimonio registrados en los tribunales eclesiásticos. ${ }^{46}$ Desde finales del siglo XII los canonistas se esforzaron por establecer normas más claras que definieran la legitimidad de un matrimonio, dejando de hecho un margen relativamente amplio para la tolerancia de uniones estables más o menos informales ${ }^{47}$. Sin embargo, cierta transigencia no significaba en absoluto aprobación. La Iglesia intentó regular y combatir en lo posible estas prácticas a medida que se desarrollaba el derecho canónico y se organizaba un aparato burocrático que articulase los tribunales eclesiásticos. Ésta no era ni mucho menos una actitud única de la jerarquía eclesiástica; los numerosos conflictos hicieron tomar conciencia a un sector amplio y creciente de la población de la necesidad de una regulación racional del matrimonio y por ende de las relaciones sexuales. Así fue reprendido y acusado Rodrigo de Catafurda «por haber dicho y porfiado hacía 14 años que la simple fornicación no era pecado mortal y que vivía mal y amancebado muchos años». El rechazo se hace general en los casos manifiestamen-

45 Jean-Louis FLANDRIN, «Répression et changement dans la vie sexuelle des jeunes» en idem, op. cit., Le sexe et l'Occident..., pp. 281-283.

46 vid. Martin INGRAM, op. cit., Church Courts...

47 vid. James A. BRUNDAGE, «Carnal delight: Canonistic theories of sexuality» en las Actas del $5^{\circ}$ Congreso Internacional sobre Derecho Canónico Medieval, publicadas en Monumenta iuris canonici, Subsidia, vol. 6, 1980, pp. 361-385; idem, «Marriage and Sexuality in the Decretals of Pope Alexander III» en Filippo Liotta (ed.), Miscellanea Rolando Bandinelli Papa Alessandro III, Siena, 1986, pp. 59-83.

Actitudes religiosas en la Edad Moderna Hispania Sacra 53 (2001) 
te ilegítimos y escandalosos, como ocurre con los curas amancebados. ${ }^{48} \mathrm{La}$ caótica y nada ejemplar situación de la Iglesia a finales de la Edad Media y durante el Renacimiento favorecía que actitudes críticas, cínicas o de simple laxitud moral encontraran fácil justificación. No es raro escuchar en esta época agrios lamentos contra los sinsabores de la vida conyuga ${ }^{49}$, llegando en algunos casos a cuestionar del todo su valide $\mathrm{z}^{50}$. Los movimientos reformistas protestantes reaccionarán aun más radicalmente contra esta situación, favoreciendo no sólo un proceso de moralización social, sino sobre todo exaltando el matrimonio y las responsabilidades familiares.

En el siglo XVI la Iglesia ya tenía capacidad suficiente para adoptar medidas efectivas que evitasen las uniones ilegítimas que tanto escándalo causaban: «quien está amancebado, con peligro de tornar a pecar, no debe ser absuelto sin que primero se aparte con propósito de nunca tornar a ello» ${ }^{51}$. Como ya adelantamos, la confesión jugará un papel fundamental en el proceso de Reforma Católica. Por otra parte estos propósitos quedarían en papel mojado si además de las normas y la doctrina no se reformaba el cuerpo eclesiástico, en su cabeza y en sus miembros. La Iglesia fue consciente de la necesidad imperiosa de reafirmar su poder y sobre todo de recuperar su autoridad moral ante una población desengañada. Por esta razón era necesaria una campaña especialmente intensa contra la relajación de costumbres del clero. Los propios confesores eran perfectamente conscientes de los peligros que podía entrañar la confesión de pecados de índole sexual y son varios los que advierten sobre este asunto ${ }^{52}$. De ahí el interés inquisitorial en la persecución de confesores solicitantes $^{53}$. Sólo un clero renovado moralmente y formado doctrinalmente haría viable una progresiva implantación de las medidas contrarreformistas.

Por otra parte las prácticas y creencias más extendidas y profundamente arraigadas eran las que concernían a las relaciones sexuales esporádicas o mercenarias, disociadas de cualquier vínculo conyugal más o menos informal. «No era pecado mortal tener acceso y copula carnal con una moza pagándoselo o queriendo ella», confesará el labrador Juan Velázquez, aunque otros como

\footnotetext{
48 vid. nota 34

49 Francisco de Tampadilla (molinero, 1618-1619): «en ocasión de tratar lo mal que lo pasaba con su mujer dijo que era mejor estar amancebado que no mal casado».

50 Juan HERNÁNDEZ (labrador, 1592-1593): «estando en conversación con ciertas personas y como una de ellas le preguntase que porque no se casaba un pariente suyo, él había dicho que para qué había de casar pues por cuatro cuartos podía cumplir su deseo en la casa pública».

51 Martín DE AZPILICUETA, op. cit., capítulo 16.

52 Martín DE AZPILICUETA, op c cit., capítulo 16, y Bartolomé de Medina, op. cit., capítulo XVIII.

53 vid. Adelina SARRIÓN MORA, Sexualidad y confesión: la solicitación ante el Tribunal del Santo Oficio (siglos XVI-XIX), Madrid, 1994; Juan Antonio ALEJANDRE, El veneno de Dios. La Inquisición de Sevilla ante el delito de solicitación en confesión, Madrid, 1994.
} 
Juan de Aramendía dirán incluso que «no era pecado y que estaba bien», rechazando toda connotación pecaminosa. Efectivamente, las relaciones entre un hombre y una mujer solteros, sin ningún tipo de vinculación o impedimento (libres), apenas entrañaban escrúpulos morales «especialmente pagándoselo $o$ teniendo intención de casarse con ella». La confusión y el uso llegan a tal extremo que en la práctica se equipara al mismo nivel la fornicación tenida con mujer soltera, contando con su consentimiento previo, con la tenida con prostituta, también con su consentimiento, esta vez asegurado por el pago. La única diferencia contemplada entre un tipo de relación y otro era de índole formal: el pago de la cantidad estipulada. Precisamente será el impago y no el acto en sí el único motivo de injusticia tenido en cuenta, ignorando cualquier otra consecuencia en el fuero interno del individuo. Como en cualquier otra transacción cotidiana uno estaba moralmente obligado a pagar ${ }^{54}$, pero una vez que la cantidad había sido satisfecha «era como los huéspedes en el mesón, que pagando la posada no debían nada» o «como una mula de alquiler, que se daba dos reales y que así pagándoselo a las mujeres publicas no era pecado». Estas opiniones solían ser defendidas con auténtica convicción y vehemencia: el mismo Bautista de Arana que utilizaba el alquiler de mulas como símil sobre el que sustentar sus afirmaciones insistía en «que si fuese necesario él lo daría por escrito»; Bartolomé de Vañares, por su parte, «no lo confesaría porque lo tenía por no pecado y que reprendiéndole dijo: '¡Válgaos el diablo! Que yo nunca tal oí en mi vida ni clérigo me lo ha dicho'»; después de una dura jornada de trabajo en el campo Miguel de Ataun fue reprendido por retozar con una moza, «ande señora», contestó, «déjenos holgar que a los religiosos y clérigos o casados se había de estorbar estas cosas por el grave pecado que cometen en ellas, pero nosotros siendo solteros no pecamos en esto», aunque estuviese medio borracho; a los reproches de algunos compañeros por haber estado en «cierta casa», el labrador Medel Pérez contestará airado, "jVálgame Dios! No debe ser tan gran pecado pues lo consiente el Rey y el Papa». De nuevo nos encontramos con la actitud ambigua de las autoridades, civil y religiosa, con respecto a la sexualidad no conyugal. Por una parte la Iglesia consideraba toda relación sexual pecaminosa en cualquier circunstancia, incluso entre esposos, únicamente tolerada cuando iba estrictamente encaminada a la procreación. Esta posición extrema se conjuga, por chocante que parezca, con la existencia justificada de prostíbulos oficiales. De este modo tanto las relaciones encaminadas a la procreación como las tenidas en el burdel municipal eran reducidas a la categoría de mal menor. En este contexto de confusión moral no pueden extrañarnos ninguna de las declaraciones de los encausados.

54 Martín de TORRECILLA, op. cit., p. 648.

Actitudes religiosas en la Edad Moderna

Hispania Sacra 53 (2001) 
Como es bien sabido, el control de las mancebías era competencia de las autoridades municipales y su funcionamiento estaba perfectamente regulado. Las razones que se argüían en defensa de los burdeles públicos eran de índole moral, económica, sanitaria y de orden público. Su existencia quedaba totalmente justificada. Sobre esto Manuel Rodríguez Lusitano afirmaba: «lícito es a los que rigen permitir que en alguna parte de la ciudad estén mujeres malas, como después de Sant Agustín lo tiene Santo Thomas. Con condición que el lugar donde están sea conforme lo que ordena el derecho»; añade además que también lo es proveer a estas mujeres de casas en aquel lugar «no con intención principal de que en ellas se ofenda a Dios, sino para que vivan en ellas», así mismo también defiende la conveniencia de que tengan patronos para defenderlas de sus «rufianes» y para «ver si tienen enfermedad contagiosa». ${ }^{55}$ Por estos testimonios parece clara la aceptación de este hecho, tenido como un mal hasta cierto punto inevitable. Las mạncebías, por tanto, quedaban justificadas moral y socialmente. Por medio de ellas se evitaba que las mujeres honestas fueran forzadas y no perdieran su virtud; de este modo unas pocas mujeres que ya habían sido corrompidas podían servir, sin causarlas por eso mayor daño, a un número mucho mayor de hombres. Otra razón importante era la de evitar la sexualidad contra natura, un pecado de extrema gravedad ya sea como molicies ${ }^{56}$ o peor aún como pecado nefando o bestialismo ${ }^{57}$. Si se mantenía el control sobre estas mancebías con patronos, higiene, situándolas en sitios apartados para evitar la tentación y prohibiendo la entrada a los casados, se estaría, según esta particular visión, ayudando a mantener un orden moral ${ }^{58}$. Precisamente estas fueron las razones que aportaba un sector importante de la Iglesia, liderado por los dominicos, a finales de la Edad Media y comienzos de la Moderna en defensa de dichas mancebías. Como declarará Villalobos: «es lícito permitir las rameras en la república para evitar otros males $\rangle^{59}$. Esta opinión aun se mantendrá hasta bien entrado el siglo XVII. En 1623 será el propio Felipe IV quien ordene el cierre de todas las mancebías tras llegar a la conclusión de que éstas no sólo no evitaban males, sino que

\footnotetext{
55 Manuel RODRÍGUEZ LUSITANO, op. cit., fol. 499 y 500.

56 Juan de Sevilla (zapatero, judío, 1582-1583) «había un año que diciéndole un mozo suyo que había tenido ciertas poluciones, le respondiera y dijo no hiciese aquello que mujeres había mundanas y pagándoselo [no tendría que] hacer tanto pecado como lo hacía en la cama».

57 Lorenzo Abad de Ameçaga (clérigo, 1605-1606): «si los hombres habian de ir a las bestias que era menos pecado ir a mujeres casadas donde no hubiese otras libres» y más adelante «tratándose cómo en Valladolid habían quemado un hombre por el pecado nefando, había dicho que a trueque de no ir a bestias mejor fuera ir a mujeres aunque fueran casadas, que no era tanto pecado».

58 Olwen HUFTON, op. cit., p. 304.

59 Enrique DE VILLALOBOS, op. cit., fol. 381.
} 
además eran la causa de los suyos y por ende de los de todo el reino. En realidad era una cuestión de coherencia con el signo de los tiempos.

Parece ser que no sólo las autoridades civiles sino especialmente las eclesiásticas aceptaban la prostitución tutelada por las autoridades por la función social que se le otorgaba. El problema que no contemplaron fue la confusión que creaba esta actitud ambigua. Jaime de Corella lo explica y se lamenta de este modo:

\footnotetext{
«P. Padre, acusome que después de la última confesión he pecado tres veces con una mujer pública.

C. ¿Y juzgaba vuestra merced que el llegar a mujer pública era pecado mortal? Pregunto porque mucha gente vulgar no sabe hacer distinción entre ser permitida una cosa a ser lícita. Por ver que en muchos lugares por evitar mayores daños se permiten casas públicas, ( $\mathrm{O}$ h Santo Dios, que a tanto ha llegado la malicia y licencia humana!), juzgan que es lícito el llegar a semejántes mujeres. $Y$ es necesario que el confesor les advierta que esa permisión no da licencia para que nadie peque» 60 .
}

¿Pero cómo no confundir lo tolerado y lo debido si incluso «el Papa permitía en Roma que las mujeres anduviesen descubiertos los pechos»?61. Un hijo de un tal Juan Alonso fue testificado por simple fornicador ante la Inquisición. No conforme con su proceso, decidió viajar a Roma a denunciar la injusticia de la que, a su parecer, era objeto. Allí terminaría descubriendo amargamente el error en el que se encontraba al ser penitenciado de nuevo y tener que volver a abjurar, esta vez de vehementi. El hecho de que la autoridad civil promoviera mancebías públicas y la Iglesia las justificara era suficiente motivo para crear un estado de confusión moral notable ${ }^{62}$.

El estado de viudedad constituía también una fuente constante de conflictos. Comúnmente se consideraba que a los viudos les resultaría más difícil mantenerse castos después de la muerte de su cónyuge porque ya habían disfrutado de los placeres de la carne durante su vida en matrimonio. Martín de Azpilicueta lo explica así:

60 Jaime DE CORELlA, op. cit., Práctica de el confessonario..., capítulo 6, caso 32.

61 Como dijera Juannes de Catategui (labrador y carpintero, 1605-1606) porque «había oído decir que en Roma andaban las mujeres los pechos descubiertos y que el Papa les permitía andar así porque los hombres no hiciesen herejías».

62 Aunque no sólo moral. La confusión entre lo que era tolerado y lo que era lícito estaba también directamente relacionado con la difícil distinción entre delito y pecado, con todo lo que esto implica; vid. Bartolomé Clavero, «Delito y pecado: noción y escala de transgresiones» en Francisco Tomás y Valiente (dir.), Sexo Barroco y otras transgresiones premodernas, Madrid, 1990, pp. 57-89. 


\begin{abstract}
«más fácil cosa es guardar la virginidad que la castidad viudal, y que mayores son las guerras que padecen las casadas, que de tarde en tarde se ayuntan con sus maridos, que las monjas, que nunca se ayuntan con ellos, que es gran consolación para el estado clerical y virginal angélico» 63 .
\end{abstract}

Tanto es así que de hecho este y otros autores los consideran más proclives a la delectación morosa ya que existía el riesgo de que «estando viudo o viuda le vinieren a la memoria las copulas matrimoniales de tiempo pasado» ${ }^{64} \mathrm{y}$ por medio de tales recuerdos producirles «delectación carnal.» En realidad el problema era mucho más simple. Una alta mortalidad y una escasa esperanza de vida hacía que muchos matrimonios quedaran truncados siendo sus cónyuges todavía muy jóvenes. Quedaba por tanto un buen grupo de personas que pese a todos los escrúpulos sociales y morales eran de hecho y de derecho personas libres de todo vínculo a todos los efectos. Libres por tanto para casarse de nuevo... o acudir a la mancebía. De esta opinión era Juan Saenz Tovera, labrador y vecino de Logroño, ya que según él «tener que hacer carnalmente un hombre viudo que estaba sin mujer, o un mancebo libre, con una mujer de la mancebía no era pecado mortal, pero que si era casado pecaba mortalmente con cualquiera mujer que no fuese la suya». Si en general se consideraba que la mujer tenía un carácter más endeble y por tanto más proclive a las debilidades de la carne, cuánto más las viudas, que ya habían catado estos placeres. Pero la realidad vuelve a imponerse a los prejuicios y la moralina. La viudedad significaba para muchas mujeres, todavía jóvenes, caer en el abandono y la más absoluta de las miserias. En estas circunstancias, como ocurrirá con algunas solteras pobres, surgirá la prostitución ocasional a cambio de dinero o algunos obsequios, tal como hacía Juan Pérez «que se igualaba con una mujer viuda o soltera por un tanto para que le consintiese tener acceso y cópula carnal con ellas». Sin embargo, apenas hay mención a este tipo de circunstancias en los tratados de moral y los manuales de confesores ${ }^{65}$.

En cualquier caso la ambigüedad había llegado a arraigar hasta en el mismo lenguaje. Una rápida consulta al Tesoro de la lengua Castellana o Española

63 Martín DE AZPILICUETA, op. cit., fol. 489.

64 ibid., capítulo 16.

65 «Otras circunstancias hay que no sacan al pecado mortal de su especie, haciéndole de mortal venial: pero disminuyenle algún tanto su gravedad, como si una mujer compelida de miedo o de gran pobreza consintiese en un acto ilícito, pecaría mortalmente, mas no tanto como si voluntariamente sin estos motivos consintiera. Destas circunstancias no está muy averiguado entre los Theologos si se han de confesar», Bartolomé de Medina Capítulo IX. Del examen y differencia de las circunstancias de los peccados, op. cit., fol. 16 y 17. Con relación a este comentario años más tarde Jaime de Corella escribirá lo siguiente respecto al estupro: «pero el sentir de Medina me parece verdadero; porque las mugeres son fáciles, y quando son repetidos los ruegos, no parece saben resistirse a ellos», Jaime de Corella, Practica de el confessonario..., op. cit., fol. 100. 
(1611) de Sebastián de Covarrubias nos da una muestra clara de lo dicho. En la entrada correspondiente al término Manceba nos encontramos con la siguiente definición:

\begin{abstract}
«Este término se toma siempre en mala parte, por la mujer soltera que tiene ayuntamiento con hombre libre, porque esto suele comúnmente acontecer entre mozos y mozas; pero confúndese la significación entendiéndose a significar cualquiera ayuntamiento que no sea legítimo, cuando es continuado»;
\end{abstract}

la entrada correspondiente a Mancebía es también muy interesante:

«Puede significar la junta de los mancebos y mozos solteros; pero de ordinario significa el lugar o casa pública de las malas mujeres».

En efecto, Covarrubias se hace eco de los usos populares, en su concepción de la sexualidad y sus implicaciones sociales, que llegan a impregnar el habla cotidiana de connotaciones muy significativas.

Resulta difícil establecer una delimitación clara entre la prostitución y otras prácticas sexuales. Como hemos visto, los propios contemporáneos nos muestran a través de sus testimonios una imagen ambigua. Esta es la razón por la cual las autoridades creen necesario aislar físicamente a las prostitutas en un edificio especial, someterlas al control de un padre y obligarlas a vestir atuendos muy determinados para que pudieran ser identificadas con facilidad; $y$, en sentido inverso, la imposición de una moral mucho más severa al resto de mujeres, sobre todo en familias con ciertas pretensiones, obligándolas a mantener el ideal de recato como norma básica de comportamiento. Investigadores como Ruth Mazo Carras y James A. Brundage han insistido en la dificultad que entraña la aplicación de la categoría prostitución a tiempos tan lejanos, ya que no parece que éste corresponda exactamente al significado y connotaciones que hoy en día le otorgamos ${ }^{66}$. Efectivamente, este concepto puede considerarse tanto una categoría moral, si se toma la promiscuidad como elemento definitorio esencial, como una categoría legal, si se considera principalmente como un comercio con especiales implicaciones de orden público. En realidad ambas categorías quedan entrelazadas en los tratados de los canonistas medievales. Partiendo de la estricta visión de la sexualidad de San Jerónimo y de su definición de prostitución basada en el concepto de promiscuidad, intentarán

66 «To write the history of prostitution is to impose a modern category on the past» dirá Ruth Mazo Carras, «Sex, Money, and Prostitution in Medieval English Culture», p. 201, en J. MURRAY y K. EISENBICHLER (eds.), Desire and discipline: Sex and sexuality in the Premodern West, Toronto, 1996, pp. 201-216.

Actitudes religiosas en la Edad Moderna

Hispania Sacra 53 (2001) 
mantener un difícil equilibrio con las ligeramente más comprensivas tesis de San Agustín que otorgaba a la prostitución una función social, considerándola un mal menor que era necesario tolerar para evitar daños mayores. Según Brundage, con esta postura más bien incoherente, los canonistas, como después los casuistas, trataban de convertir los principios abstractos de la teología en normas de comportamiento practicables en el día a día ${ }^{67}$. En cierto modo alcanzaron su objetivo, pero al coste de sembrar confusión y ofrecer argumentos para justificar la laxitud moral. Sin embargo, todo esto sólo es una parte de la verdad. No podemos reducir un fenómeno tan complejo a una cuestión de ignorancia doctrinal y moral distraída. Hay algo más.

Una vez que el reo ha caído en la cuenta de su error y ha sido adecuadamente reprendido, veamos lo que tiene que decir en su defensa. Muchos de los acusados alegan como atenuantes ira, burla, simplicidad, ignorancia o el abuso de bebida, pero junto a esto nos encontramos con una justificación mucho más general: el simple y llano desconocimiento. Dejemos que los propios interesados, los encausados, se expresen. Martín de Navascués, joven pamplonés de 19 años, fue testificado en 1586 porque «había dicho riéndose que no era pecado mortal tener acceso carnal con mujeres libres», hasta aquí nada especialmente novedoso excepto por el matiz de incredulidad que la risa de Martín expresa al ser reprendido por tal afirmación. Ante la Inquisición caerá en la cuenta de su error y esta vez sin reírse alegará en su defensa «ser cristiano viejo» y además «confesó todo lo testificado, y declaró que no entendía que era pecado el tal acceso carnal y que estuviese prohibido decir lo susodicho por la santa ley de Dios». Martín es absolutamente sincero en su declaración de culpabilidad. Por otra parte observamos que sí conocía cierta posibilidad de pecado aunque ignorase totalmente que decir ese tipo de cosas estuviese perseguido y penado. En ningún momento se percibe un intento de justificar una actitud que se sabe impropia, tampoco se intenta engañar al tribunal y no es tanta la ignorancia de la doctrina como a simple vista pudiera parecer. En cierto modo Martín tenía razón, ignoraba que esas declaraciones estuviesen prohibidas porque efectivamente hasta ese momento no lo estaban. Hay algo más que simple ignorancia detrás de todo esto.

A la hora de la defensa el reo generalmente probará no solo ser cristiano viejo, sino además «buen cristiano temeroso de Dios y de su conciencia» y «de buena vida y fama». Paradójicamente, para los encausados estas defensas no entran en contradicción con la acusación de simple fornicación probada y admitida por ellos mismos. «Se trata de un cristianismo vago, genérico y sociológico» dirá con razón Contreras ${ }^{68}$, pero la explicación a este fenómeno no

67 James A. BRUndAGE, «Prostitution in Medieval Canon Law» en Signs, 1, 1976, pp. 825-845.

68 Jaime CONTRERAS, op. cit., El Santo Oficio..., p. 633. 
hay que buscarlo en un supuesto «paganismo» ancestral, como él mismo apunta, ni mucho menos, sino en actitudes de raíz estrictamente tardomedieval. La ignorancia manifiesta de la doctrina básica de la Iglesia no estaba de hecho en contradicción con la pertenencia a este cristianismo genérico. El cristianismo, entendido en un sentido amplio, no era lo que hoy entendemos como una opción religiosa personal; de hecho será precisamente entonces cuando se «invente», por así decirlo, el concepto de confesionalidad. Hay que tener en cuenta el cambio de actitud de la Iglesia y la sociedad en general en relación con la sexualidad y la vida matrimonial durante esta época. Por todo ello era lógico que existieran desajustes entre la arraigada mentalidad preconfesional y la nueva sensibilidad tridentina ${ }^{69}$.

Para empezar, las actitudes y los usos con respecto a la sexualidad estaban estrechamente vinculados al concepto de pecado. Ni que decir tiene que al igual que otras categorías, la de pecado adquiere distintos significados, variables según el contexto histórico. Partimos de una realidad objetiva que es que la fornicación, como dijimos anteriormente, atenta contra el sexto mandamiento, pero esta sencilla afirmación da pie a diversas interpretaciones. La explicación teológica la tomaremos de Bartolomé de Medina:

«mándanos aquí Dios tener limpieza en lo interior, y en lo exterior de las almas, y en los cuerpos, porque como dice San Pablo somos templos de Dios, y así es razón que no los ensuciemos con cosas deshonestas, y sucias, sino que hagamos en todo como miembros de Christo cordero inmaculado» 70 ;

hablando de pecado se hace necesaria una explicación moral:

«engendra este vicio ceguera en la mente, y quita el uso de la razón, hace a los hombres bestias. Síguese de ella inconsideración, inconstancia, precipitación, amor propio, aborrecimiento de Dios, deseo demasiado desta vida, horror de la muerte y del futuro juicio, desesperación de la felicidad eterna, infamia, destrucción, y desconcierto de toda la vida» 71 .

Ambas explicaciones se complementan entre sí aunque se formulen desde perspectivas distintas. Pero aun cabe otra interpretación, más mundana, que nos acerca realmente al contexto cultural de la época:

69 vid. John Bossy, Christianity in the West, 1400-1700, Oxford, 1987.

70 Bartolomé DE MEDINA, op. cit., fol. 93.

71 ibid., fol. 11.

Actitudes religiosas en la Edad Moderna

Hispania Sacra 53 (2001) 
«este [vicio] quita el sentido: hace a los hombres bestiales, atormenta a los que le siguen, consume las riquezas, acorta la vida, daña la salud, roba la fama y la honra, y su contentamiento es breve y bestial» 72 .

Las implicaciones del pecado, por tanto, son muy diversas: las hay también físicas, sociales y económicas. Estas consideraciones no eran tenidas por secundarias, más bien al contrario, se situaban de hecho a la par de las preocupaciones estrictamente morales. Algunos de estos tratadistas estipulan conforme a las leyes y la costumbre los efectos nocivos que sobre la convivencia y las relaciones sociales podían tener algunas de estas prácticas inmorales. Este daño adicional, que trasciende el fuero interno, es el que recibe el nombre de injusticia. Estos daños se han de restituir de algún modo. Lo cual se contempla de forma muy clara en casos de fornicación cualificada tales como el estupro y el adulterio, cuyas implicaciones sociales llegarán a ser de extrema importancia y, en la práctica, más que las morales. ¿Pero a quien se dañaba en las simples relaciones entre solteros?, si ambos consentían o se pagaba lo convenido, ¿qué injusticia podría cometerse? Podría parecer que los argumentos teológicos o simplemente morales fuesen a veces demasiado inasibles para gentes con escasa formación religiosa. Al igual que la intervención divina se manifestaba por medio de los milagros, era necesario que el pecado pudiera «verse», que la realidad sensible lo reflejara de alguna manera. Villalobos, siguiendo a los canonistas tardomedievales, tratará de darnos la respuesta exponiendo en este sentido que la simple fornicación es pecado mortal «porque va contra la vida del que ha de nacern. ${ }^{73}$ Se pone así en relación directa con algunos aspectos del pecado contra natura. ${ }^{74} \mathrm{El}$ fin natural de la relación sexual debía ser la procreación, así lo entendían teólogos y moralistas. Pero la interpretación popular podía llegar a ser bien distinta al confundir consecuencias con fines. De este modo se justificaba la intención moral por el resultado del acto. Domingo de Aibar salió al auto de 1582 por decir «que por multiplicar no era pecado queriendo dar a entender que por tener acceso y copula carnal con mujeres no era pecado» y una vez reprendido por los testigos añadió «que no fuese pecado el tal acceso sino fuese con bestias». En cierto modo el castigo-penitencia inquisitorial era una forma de reparar la injusticia hecha a la comunidad por el escándalo causado con la proposición.

Está claro que pese a todo no se trata sólo de amoralidad o simple ignorancia. Se trata de una visión diferente de la sexualidad, la moral y el mundo en

\footnotetext{
72 ibid., fol. 169.

73 Enrique DE VILLALOBOS, op. cit., fol. 381.

74 Así define Enrique de Villalobos el pecado contra natura: «es el que se comete contra lo que la naturaleza pide en ese acto, o contra lo que es necessario para la divina generación», ibid.
} 
general. La sexualidad, como otras muchas facetas de la vida cotidiana, en una etapa premoderna estaría marcada por un tipo de mentalidad que podríamos calificar como concreta y pragmática, basada en la experiencia sensible de la realidad acumulada y trasmitida a través de la costumbre. Según Lucien Febvre «para los hombres del siglo XVI la experiencia era el hecho de experimentar, de observar, de registrar un fenómeno tal cual, un acontecimiento que se produce por sí mismo, al margen de toda intervención y de toda voluntad particular de producirlo o no producirlo» ${ }^{75}$. Todavía sumidos en este contexto a finales del siglo XVI y principios del XVII, hay una tendencia a una reducción de todas las variantes de la actividad sexual, sin hacer apenas distinción con respecto a las circunstancias que la rodeaban. Serán las repercusiones sociales las que definan la existencia de alguna culpabilidad, no será tanto la carga moral del acto como la injusticia derivada de éste lo que cause cierta animadversión $^{76}$. Por eso únicamente se percibe un rechazo social unánime hacia el estupro y el adulterio. Algunos de los pecados considerados contra natura son aceptados como un mal menor por la gente (molicies) pero otros como una clara anomalía (bestialismo). Hasta entonces las pulsiones sexuales se consideraban un fenómeno naturalmente determinado, que en principio escapaba a la voluntad y a la razón. No se contemplaba la posibilidad de educar, reprimir o controlar la sexualidad: o se renunciaba a ella (y con ella al mundo) o se toleraba como un mal inevitable. De ahí que desde el punto de vista eclesiástico tradicional se considerara el matrimonio una concesión hecha a los incontinentes o se permitieran legalmente uniones estables informales aunque no legíti$\operatorname{mas}^{77}$. El testimonio del pañero Diego Vayo, vecino de Ortigosa de 50 años de edad, resulta enormemente ilustrativo. Fue testificado entre 1614 y 1615 ante el Santo Oficio por contar, entre otras muchas cosas, la siguiente historia: habiendo

75 Más adelante concluye diciendo: «vivieron muy a gusto en un mundo singular en el que los fenómenos no están identificados y el tiempo no establece un orden riguroso entre los acontecimientos y las existencias [...] Y fueron todos, no sólo los incultos, los simples o los ignorantes» en Lucien Febvre, Le problème de l'incroyance au XVIe siècle, París, 1942 (edición española: El problema de la incredulidad en el siglo XVI, Madrid, 1993, pp. 305 y 307).

76 El rico hidalgo Juan Alonso (1585) no tuvo más remedio que admitir «que podría ser haber dicho algunas veces que la simple fornicación no era pecado, pero que no se acordaba, pero que dijo que no era pecado sino de restitución»; por su parte Baptista de Arana (1590-1592) declararía que «no era tan grande pecado el conocer a las mujeres públicas carnalmente como a otras mujeres, o que pagando lo que les habían ofrecido por el tal acceso no tenían pecado de restitución los que trataban con ellas, y que aquello lo mostraría en un libro». Es interesante observar no sólo que los reos son gente adinerada, sino que además ambos arguyen haber leído tales afirmaciones en sendos libros («un confesonario» en el caso de Juan Alonso).

77 Jean-Louis FlANDRIN, op. cit. en idem, Le sexe et l'Occident..., p. 282; también vid. Anna Benvenuti PAPI, «La santità nel matrimonio: momenti e motivi di una contradizione» en M. DE GIORGIO y Ch. KLAPISCH-ZUBER (eds.), Storia del Matrimonio, Bari-Roma, 1996, pp. 63-90. 
pecado un hombre por el sexto mandamiento lo mandó Dios llamar, y una vez estuvo frente a su divino rostro éste le preguntó que por qué razón había pecado del dicho mandamiento, a lo que él contestó: «señor, ¿para qué me disteis vos la canalla?». Por su parte el estudiante Hernando de Buxanda salió al auto de 1586 porque «dijo que no era pecado mortal dormir carnalmente un hombre con una mujer porque no mandaría Dios que se echase con una yegua o con una puerca». Partiendo de esta mentalidad y del contexto que le da sentido, la lógica de estas afirmaciones es aplastante y en cierto sentido (casi) inapelable. No se trataba de ningún sistema de pensamiento establecido y homogéneo. Carece de toda teorización y formalidad. Se trata más bien de un «estilo de pensamiento» ${ }^{78}$, de un patrón que permite percibir la realidad de una determinada manera. Me gustaría pensar que Menocchio estaría de acuerdo conmigo.

En cualquier caso esta forma de interpretar la realidad se verá paulatina pero inevitablemente desplazada por una concepción más racionalista del mundo, comenzando precisamente por aquel aspecto esencial que impregnaba y daba sentido a todo: la religión. La extensión de la disciplina confesional tridentina será un importante factor en este sentido. El éxito de la implantación de este nuevo orden dependería por tanto de su grado de socialización. Por medio de métodos persuasivos, represivos, ejemplares o de refuerzo se pretendía el adoctrinamiento general de la sociedad. No podemos, sin embargo, reducir un problema tan complejo únicamente a términos dialécticos, enfrentando a una minoría dominante «controladora» a la gran masa de «controlados». Resulta lógico pensar que un plan tan ambicioso no podía establecerse por simple imposición, requería también de cierto grado de aceptación social ${ }^{79}$.

La simbiosis entre Inquisición y confesión fue uno de sus más eficaces instrumentos. No será en la fuerza represiva sino en la persuasiva donde encontrará su fuerza, debido precisamente a que ambos tribunales, el de la fe y el de la conciencia, requerían de delaciones, es decir, de la participación activa de los fieles, para ponerse en marcha. Para que fuera viable era necesaria la existencia de una corriente de opinión afín o por lo menos receptiva a la sensibilidad contrarreformista. Podemos decir que para el último tercio del siglo XVI este grupo era ya muy significativo, si no mayoritario, según se deduce del número de delatores registrados en las Relaciones de Causas de la Inquisición. La capacidad de influencia de estos «agentes libres», personas normales mejor for-

$78 \mathrm{El}$ término lo formula y desarrolla J. Peter DENNY, «El pensamiento racional en la cultura oral y la descontextualización escrita», en David R. OLSON y Nancy TORRANCE (eds.), Cultura escrita y oralidad, Barcelona, 1995, pp. 94-126.

79 Sobre la aplicación de la teoría del 'control social' al caso inquisitorial vid. Bartolomé Escandell, «La Inquisición como dispositivo de control social y la pervivencia actual del 'modelo inquisitorial'» en Ángel Alcalá y otros, Inquisición española y mentalidad inquisitorial, Barcelona, 1984, pp. 597-611. 
madas o informadas, podría haber sido mucho más grande de lo que comúnmente imaginamos. Lope de Perea mantenía la opinión de que «no era pecado tener mancebas» pero alguno de los que le oyeron le reprendieron, así que el tal Lope se retractó, tanto es así que él mismo acabaría confesando voluntariamente ante el tribunal del Santo Oficio. Sin embargo, en otros muchos casos el reo es apresado en contra de su voluntad. No debemos olvidar que la delación era también una cuestión religiosa y moral. Jaime de Corella advertirá en su comentario a las 65 proposiciones condenadas por Inocencio XI que cualquiera que mantuviese alguna de ellas (entre las que estaba incluida la de simple fornicación) «debe ser delatado al Tribunal de la Santa Inquisición; y el que sabiéndolo no delatare al transgresor, incurre en excomunión mayor 'latae sententiae': fulminada por el Tribunal Supremo de la Inquisición, en su decreto de 24 de Iulio de 1679.» Por su parte, fray Anselmo Gómez venía a reforzar esta idea desmintiendo la siguiente opinión: «aunque sea evidente que Pedro es hereje, no hay obligáción a delatarle sino se puede probar», que de hecho condena explícitamente ${ }^{80}$.

Un lugar común entre los historiadores es que la confesión voluntaria ante el tribunal se debía principalmente a la esperanza de ser tratado con más benevolencia y sobre todo por el temor a ser delatado por otros ${ }^{81}$. Es cierto que no se puede descartar esta causa, pero sólo sería una más dentro de un contexto más complejo en el que intervenían otros factores. Bartolomé de Mendoza, estudiante alavés residente en Logroño, confesó espontáneamente porque:

\footnotetext{
«habría un mes estando en conversación con otro estudiante había dicho que tener un hombre soltero conversación y copula carnal con una mujer soltera no era pecado a su parecer, queriendo realmente decir que el pecado con la mujer soltera no era tan grave como en la casada, y así lo había dicho por yerro e inconsideración y que luego se lo reprendieron $[. .$.$] había caído en su yerro»$
}

En este caso vemos también como la opinión espontánea de una persona puede convertirla en agente de la ortodoxia sin necesidad de caer necesariamente en la delación. Bartolomé no sentirá ningún temor en este sentido sino que:

«arrepintiéndose dello se había ido a confesar. Y confesado sacramentalmente le había absuelto su confesor. Y que después se había confesado otra vez con otro confesor y por su mandado manifestaba en el Sancto Oficio haber dicho las dichas palabras».

80 Anselmo GómEZ, op. cit., fol. 116.

81 Sobre la llamada pedagogía del miedo inquisitorial vid. Bartolomé BENNASSAR, «Modelos de la mentalidad inquisitorial: métodos de su 'pedagogía del miedo'», en Ángel Alcalá y otros, op. cit., pp. 174-182.

Actitudes religiosas en la Edad Moderna

Hispania Sacra 53 (2001) 
Es aquí donde vemos entrar en acción a uno de los agentes activos más importantes en este proceso: el confesor. Ya no será el miedo a ser delatado sino la necesidad de ser absuelto lo que provoque la comparecencia. No podemos dejar escapar un detalle, será el segundo confesor y no el primero el que ordene la autodelación, el primero posiblemente no compartía o ignoraba la posición oficial al respecto. Como ya vimos, muchos manuales de confesores ordenaban expresamente negar la absolución por ciertas faltas sin delatarse primero ante la Inquisición. Aunque la obligación de frecuentar los sacramentos y el prestigio y el temor que inspiraba una institución como la Inquisición fueron factores de extrema importancia, la clave para la inculcación de los nuevos valores residía en la aceptación voluntaria de éstos por parte del reo-penitente. El móvil principal no fue el miedo a los azotes sino el deseo de salvarse o mejor dicho, el temor a la condena eterna.$^{82} \mathrm{La}$ efectividad del confesor en este sentido dependía de su formación y de su comportamiento moral. Este clero reformado constituirá una de las principales claves para comprender el avance de la Contrarreforma y no necesariamente siempre desde el confesionario. El caso del mercero Juan Simón resulta muy ilustrativo. Aprovechando la visita del inquisidor a Santander en el año 1588, el reo decide confesar que en una conversación había defendido que la simple fornicación era un «pecado simple» y no mortal, a lo que los testigos contestes añadirán que «lo porfió mucho y que se apostó un real para vino a que no era pecado mortal y lo fueron a preguntar a un clérigo y habiéndoles dicho que era pecado mortal se convenció; y que estando el inquisidor de visita le dijeron que lo fuese a confesar porque ellos no podían dejar de irlo a decir».

Por su parte, el pastor Diego Molero, vecino de Castelruiz de 23 años de edad, fue «testificado por un fraile franciscano descalzo presbítero de que estando los dos en el campo juntos en una ermita había dicho, pues había estado en tierra de Córdoba, y lo que había visto allí era que las mujeres de veinte en veinte salían a los caminos a convidarse a los hombres. Y diciéndole que se habian de resistir las ocasiones y no se había de pecar, respondió que según fuesen las ocasiones. Y preguntándole si sabía los mandamientos dijo que sí, y que eran diez, pero que no podían los hombres dejar de pecar. Y reprendiéndoselo y amonestándole que fuese honesto dijo que el conocer y tener conversación carnal con mujer de la mancebía no era pecado mortal. Y procurándole con buenos ejemplos sacarle de aquel error dijo que con mujeres honradas y doncellas era pecado mortal, mas que con las otras no lo era, pagándoselo. $Y$ vuelto a reprender dijo: ‘ $i$ Bueno sería, padre, que todos los que van a la mancebía se fuesen al infierno!»

82 vid. Jean DELUMEAU, Le péché et la peur. La culpabilisation en Occident XIIIe-XVIIIe siècles, París, 1983.

Actitudes religiosas en la Edad Moderna Hispania Sacra 53 (2001) 
Este testimonio resulta de enorme interés. En primer lugar nos encontramos a este religioso en contacto directo con la realidad de las gentes de su tiempo, la situación se nos presenta de un modo espontáneo y cotidiano. El pastor cuenta con toda naturalidad su historia, por su testimonio vemos cómo participa de la mentalidad popular imperante con respecto a la sexualidad, pero a pesar de su presumible rusticidad nos encontramos con un hombre que ha visto algo de mundo y que conoce los principios más básicos de su religión. Defiende su punto de vista con toda vehemencia y pleno conocimiento de causa, a pesar de los infructuosos intentos por persuadirle y sacarle de su error. En vista de que de este diálogo no se han obtenido resultados positivos, será el propio franciscano quien opte por la vía punitiva acusando al pastor ante el Santo Oficio. El tribunal finalmente condenó a Diego Molero a salir al auto de fe de 1592 y a destierro por un año.

Por otra parte, la eficacia de la Inquisición podía percibirse mucho antes de aplicar ningún castigo. Una visita inquisitorial era todo un acontecimiento en la localidad. Una vez anunciada su llegada y pregonado el edicto de la fe se abría un tiempo de gracia, que junto a la prohibición de imponer penas severas durante las visitas, podría haber sido razón suficiente para animar al arrepentimiento y por tanto, a la confesión voluntaria. La publicación del edicto de la fe y toda la parafernalia de la que iba acompañado ${ }^{83}$ se convertía durante aquellos días en tema de conversación entre las gentes, más aun a partir de 1573 cuando, para sorpresa de muchos, el edicto incluyó en su lista de prácticas heréticas perseguidas las proposiciones por simple fornicación: «tratando del edicto de la fe [el labrador Diego de Villaverde] había dicho y porfiado que tener acceso y copula carnal un hombre con una mujer solteros no era pecado mortal». De este modo los inquisidores habían encontrado el modo de sacar a la luz un asunto hasta entonces obviado, introduciendo un elemento de disensión en el orden moral tolerado tradicionalmente en la localidad. Francisco de Baptista «estando con ciertas personas en la dicha villa [de Pedroso] después de haber leído el edicto de la fe, una de ellas estaba retozando a cierta mujer y se apartó con ella a alguna parte y con esta ocasión dijo: 'Hazle tal cosa, que no es pecado', diciéndolo por palabras sucias», otros jóvenes que por allí andaban reprendieron sus palabras, con lo que no sólo se arrepintió dando «muestras de haberle pesado», sino que además terminaría compareciendo voluntariamente ante el Santo Oficio.

Sin embargo, era a la hora de la sentencia cuando la Inquisición hacía patente su labor ejemplificadora. Las penas más corrientes solían consistir en ser reprendido en la sala de la audiencia, abjuración de levi y «oír misa mayor en

83 Ignacio Villa CALleja, «Investigación histórica de los 'Edictos de Fe' en la Inquisición española (siglos XV-XIX)» en Jaime Contreras (ed.), op. cit., pp. 233-256.

Actitudes religiosas en la Edad Moderna

Hispania Sacra 53 (2001) 
domingo o fiesta en la iglesia colegial de Logroño como penitente, donde se dijese la causa de su penitencia», acompañadas de otras dependiendo de la gravedad de la falta, la condición del reo, las circunstancias en las que se hubiese desarrollado el proceso y otros factores. Las multas y el destierro, por el cual se evitaba que el reo encontrara un campo abonado a la aceptación de sus proposiciones en el lugar donde solía hacerlas, eran las penas más frecuentes. Durante las décadas finales del siglo XVI y primeros años del XVII fueron comunes, además, otros métodos que nada tuvieron de persuasivos como son la vergüenza pública y los azotes, con consecuencias evidentes para el reo. La ejemplaridad de los castigo-penitencia inquisitoriales podía causar varios efectos. El más obvio es el punitivo que recae sobre el condenado, que es además reprendido e informado de su error. Con toda seguridad la próxima vez tendrá más cuidado con lo que dice o incluso con lo que piensa, independientemente de que al final persevere en sus creencias, cambie de parecer o quede confundido. El segundo efecto será el disuasorio para aquellos que mantienen opiniones equívocas y todavía no han sido delatados. A propósito de esto último es llamativo ver que de ello no se sigue necesariamente lo que podríamos llamar una lógica ocultación de la opinión sospechosa, sino que, por el contrario, son estos castigos públicos los que pueden suscitar la autodelación ante el tribunal. El tercer efecto sería la estigmatización no sólo del individuo sino también de sus descendientes, que quedarán por su causa infamados. Por último no hay que descartar un efecto reforzador para todos aquellos ya imbuidos del sistema de pensamiento contrarreformista, animados a su vez a delatar a cualquier sospechoso.

Pero sin lugar a dudas era en los autos de fe donde la aplicación de la penitencia ejemplar resultaba más notoria y, por tanto, más eficaz. En efecto, no cabe duda de que un auto era un acontecimiento público que podía causar honda impresión entre aquellos que asistían a verlo. Hernando de Gusalva, vecino de la villa de Fuenmayor confesó espontáneamente por palabras de simple fornicación y declaró que «cuando las dijo no sabía el tal acceso ser prohibido por la ley de Jesuchirsto, antes entendía era lícito, en el cual error había estado hasta que vio castigar a uno en auto público de la fe por lo mismo y entonces había venido a hacer la dicha manifestación al Santo Oficio.» Él mismo acabaría saliendo al auto celebrado en 1587 . No podemos olvidar que en el último tercio del siglo XVI y primeros años del XVII se celebraron en Logroño autos de fe regular y frecuentemente (ocho durante la década de 1580). El efecto de estas celebraciones no se ceñía exclusivamente a aquellos que podían presenciarlas en vivo y en directo, sino que después podían ser largamente referidas y comentadas en otros lugares. Este es el caso de María Perez, vecina de Ariano de 45 años, «que tratando de cierto auto que se había hecho en el Santo Oficio y diciendo como un mozo había sido azotado por haber dicho que no era pecado tener cópula carnal con una mujer soltera, la dicha rea que 
presente estaba dijo: 'a la fe no es pecado entre personas solteras si no es con clérigo o casado', y siendo reprendida se afirmó y ratificó diversas veces quedando con su opinión. Y después la susodicha confesó de su voluntad.»

Entrado el siglo XVII el número de autos celebrados va decreciendo al tiempo que las penas van perdiendo parte del rigor característico de las últimas décadas del siglo XVI: van abandonándose los azotes y aumentan las reprensiones sin sentencia. ${ }^{84}$ En efecto, parece ser que en este campo la represión más violenta pierde terreno a favor de la «pedagogía». Según Prosperi el ejercicio de esta función educativa fue posible gracias a la confesión, que sirvió como vía de comunicación directa con la sociedad católica: «los confesores se fueron pareciendo cada vez más a los inquisidores [...] con el paso del tiempo, inquisidores y confesores se intercambiaron los papeles, asumiendo los unos la función educativa y los otros la policial y represiva» ${ }^{85}$. Por un lado los confesores someterán a sus penitentes a largos interrogatorios, inquirirán no ya solo sobre sus faltas y sus intenciones, ahora también pretendían aclarar todas las circunstancias con el mayor detalle posible: si hubo escándalo, dónde, cómo, si hubo cómplices y quiénes fueron éstos... ${ }^{86}$ Por su parte los inquisidores

84 «La benignidad destos tiempos» repetirá amargamente refiriéndose a este cambio de actitud el autor del manuscrito titulado Las cosas que se han de observar y practicar en las Inquisiciones, con algunos cassos particulares y extraordinarios que me parecen dignos de notar por ejemplares, para quando suceda casso semejante, de la segunda mitad del siglo XVII conservado en la Biblioteca Nacional de Madrid, transcrito por Àngele Boetti (Biblioteca de español de la U. Toulouse-le Mirail, 1977) y comentado por Louis CARDAILLAC y Robert JAMMES, «Amours et sexualité a travers les 'mémoires' d'un inquisiteur du XVIIe siècle» en Agustín Redondo (dir.), Colloque International sur Amours Legitimes, Amour Illegitimes en Espagne (XVIème-XVIIème siècles)1984. Sorbonne, París, 1985, pp. 183-194.

85 Adriano PROSPERI, op. cit., Notas..., pp. 34 y 35.

86 «Pregunta: ¿Qué cosas puede preguntar el confesor al penitente acerca del sexto mandamiento, que es no fornicarás?

Respuesta: Que lo siguiente: Si tuvo parte con mujer casada, que es adúltero; si cayó en fornicación; si pecó con doncella; si pecó con parienta, o cuñada; si conoció parienta espiritual, o madre; o si andando en amores si paseó por su calle o habló, o hizo señas, o se puso donde la viese, o fuese vista; si envió o recibió billetes, mensajes, o dádivas, o dio músicas: si se siguió algún escándalo de sus amores, si se puso en algún peligro por ellos; si fue medianero en esto, o acompañó, o toma compañía para ello; si se afeita ella o se atrevieron para contentar el uno al otro: si cayó generalmente en otra cualquier torpe flaqueza; si se casó habiendo prometido de entrar en religión; si se casó habiendo hecho voto de castidad; si casó habiendo prometido de no casar; si se casó con parienta o cuñada; si casó con parienta legal; si casó habiendo impedimento de homicidio, o adulterio; si casó secretamente con una, y después en público con otra; si casó con otro por oír decir que su marido era muerto; si la mujer no siguió al marido donde fue; si no guardó el casado la ley del matrimonio; si después de casado conoció parienta de su mujer; si empleó mal los cinco sentidos; si se entregó a la gula; si pecó en algo desto por palabra o propósito, o deseó, o mandó, o fue caso que otro lo hiciese, o alabó a sí, o a otro por haberlo hecho» según propone Martín de Torrecilla, op. cit., fol. 307 y 308 .

Actitudes religiosas en la Edad Moderna

Hispania Sacra 53 (2001) 
se aplicaron cada vez más a la tarea de reprender y ejemplificar a los confusos o desviados que llegaban a sus manos buscando encontrar penitencia y por tanto, perdón.

El sistema contrarreformista basaba su eficacia en la acción combinada de todas sus fuerzas y agentes, movilizados para hacer partícipes de su nueva visión de la religión a todos los fieles. El resultado de esta socialización católica fue al parecer bastante satisfactorio, aunque su implantación fue limitada, lenta y costosa. Algunas dificultades se solventarán con una mejor y más coherente formación religiosa, sobre todo entre el clero, aunque esto requirió de la Iglesia un enorme esfuerzo en todos los sentidos y sus resultados solo pudieron percibirse a medio o largo plazo. Pero será la creación de un clima social favorable a la recepción de estas ideas el principal logro de los primeros momentos de la campaña contrarreformista. Eran perfectamente conscientes de sus limitaciones, su intención no era la de hacer una sociedad de santos o de teólogos, ni siquiera simplemente de cristianos, sino de católicos, con todas sus nuevas implicaciones. Por tanto, iban mucho más allá de los aspectos generales obvios (lucha contra la laxitud moral y la ignorancia doctrinal) o instrumentales (el llamado control social). Abarcando todos los aspectos de la vida y llegando a todos los grupos sociales ponían en marcha lo que pomposamente podría llamarse una auténtica «revolución confesional». Sus aspiraciones no eran del todo ajenas a las de la mayoría de los fieles, principalmente el deseo de salvación espiritual. La Reforma Tridentina les ofrecía unas señas claras de identidad, una doctrina única y una moral más rigurosa, garantizadas por una Iglesia poderosa y renovada que pretendía desterrar todas las dudas generadas por los movimientos heréticos y erigirse única depositaria de la verdad. Las conciencias serán formadas siguiendo un plan coherente. Con el tiempo la interiorización de una noción unívoca de pecado llevará a su vez a una redefinición del sentido de culpa. Pese a las resistencias lógicas su principal logro será la progresiva aceptación por los fieles de este nuevo patrón de salvación que acabarán considerando como el único válido, más aún, como el único posible. 